Cahiers $d u$ MONDE RUSSE

\section{Cahiers du monde russe}

Russie - Empire russe - Union soviétique et États indépendants

40/4 | 1999

Varia

\title{
Statisticiens des zemstva: formation d'une nouvelle profession intellectuelle en Russie dans la période prérévolutionnaire (1880-1917)
}

Le cas de Saratov

Martine Mespoulet

\section{(2) OpenEdition}

Journals

Édition électronique

URL : https://journals.openedition.org/monderusse/32

DOI : $10.4000 /$ monderusse.32

ISSN : 1777-5388

Éditeur

Éditions de l'EHESS

Édition imprimée

Date de publication : 1 novembre 1999

Pagination : $573-624$

ISBN : 2-7132-1341-X

ISSN : $1252-6576$

\section{Référence électronique}

Martine Mespoulet, «Statisticiens des zemstva : formation d'une nouvelle profession intellectuelle en

Russie dans la période prérévolutionnaire (1880-1917) », Cahiers du monde russe [En ligne], 40/4 I

1999, mis en ligne le 15 janvier 2007, consulté le 04 septembre 2022. URL : http://

journals.openedition.org/monderusse/32 ; DOI : https://doi.org/10.4000/monderusse.32 


\title{
STATISTICIENS DES ZEMSTVA
}

\author{
Formation d'une nouvelle profession intellectuelle \\ en Russie dans la période prérévolutionnaire (1880-1917) \\ Le cas de Saratov
}

LES TRANSFORMATIONS ÉCONOMIQUES RAPIDES DE LA RUSSIE de la fin du XIXe siècle à la veille de la Première Guerre mondiale, mais aussi le développement des services collectifs (d'éducation, de santé et de transport, par exemple) se sont accompagnés de l'expansion de son administration publique, au niveau local comme au niveau central. Cette évolution s'est traduite notamment par une forte augmentation des effectifs du groupe des professions intellectuelles au sens large du terme, c'est-à-dire de l'ensemble des personnes, indépendantes ou salariées, vivant de leur activité intellectuelle.

Comme dans d'autres pays européens à la même époque ${ }^{1}$, le développement de ces professions est allé de pair avec une plus grande spécialisation des fonctions exercées, une diversification interne du groupe et son élargissement à des catégories nouvelles. Parmi celles-ci, changement notable en Russie à la fin du $\mathrm{XIX}^{\mathrm{e}}$ siècle, figurent les professions intellectuelles travaillant non pas au service de l'État, mais à l'extérieur de celui-ci². À cette dernière catégorie appartiennent les professions libérales, les professions artistiques et les journalistes, mais aussi toute la sphère des professionnels employés par les zemstva, institutions territoriales

Je remercie Wladimir Berelowitch, Alain Blum, Michael Confino, Emmanuel Didier et Alessandro Stanziani pour leur lecture attentive de ce texte, leurs remarques et leurs suggestions.

1. Cf. notamment Christophe Charle, Les intellectuels en Europe au XIX ${ }^{\mathrm{e}}$ siècle, Paris, Seuil, 1996 ; Pierre Guillaume, ed., La professionnalisation des classes moyennes, Talence, Ed. de la Maison des Sciences de l'Homme d'Aquitaine, 1996.

2. Cf. Michael Confino, «Idéologies et mentalités : Intelligentsia et intellectuels en Russie aux XVII'-XIX ${ }^{\mathrm{e}}$ siècles », in M. Confino, Société et mentalités collectives en Russie sous 1'Ancien Régime, Paris, Institut d'études slaves, 1991, pp. 389-421. 
d'administration locale ${ }^{3}$. Estimé à 20000 en 1890, le nombre de fonctionnaires au service des zemstva était évalué à 80000 au début du $\mathrm{XX}^{\mathrm{e}}$ siècle ${ }^{4}$.

Jusqu'ici, en dehors de quelques ouvrages, notamment ceux de V. R. LejkinaSvirskaja et de L. K. Erman ${ }^{5}$, peu d'études ont essayé de dresser les contours précis du groupe tout entier de ces professions entre 1880 et 1917 . La tâche est d'autant plus délicate que celui-ci apparaît très diversifié. Néanmoins, quelques recherches ont étudié de manière approfondie certaines de ces nouvelles professions, citons en particulier celle de Nancy Frieden consacrée aux médecins et celle de Christine Ruane aux enseignants ${ }^{6}$.

La question du statut réel occupé par les professions intellectuelles employées par les zemstva, celle également de leurs représentations professionnelles, sociales et politiques, restent encore largement ouvertes et « semées de difficultés », comme l'a noté Michael Confino ${ }^{7}$. Il a souvent été souligné que ces membres du « troisième élément » ont joué un rôle très actif dans la gestion des affaires publiques des zemstva, au point de l'infléchir dans certains cas ${ }^{8}$. Dans le même esprit, il est également souvent noté que les administrateurs nobles de ces institutions territoriales, le « deuxième élément », ont été dépossédés d'une partie de leurs pouvoirs par le « troisième élément ${ }^{9}$. Ceci suggère deux questions : Quelle place réelle ces professionnels des zemstva occupaient-ils dans l'administration et la vie publique locales? En dehors de leur activité professionnelle, quelles étaient les formes concrètes de leur insertion dans la vie politique et sociale locale?

L'étude de la composition et des pratiques d'un des groupes professionnels du « troisième élément » peut apporter quelques éléments de réponse à cette double interrogation, elle peut également aider à mieux comprendre la part prise par ces hommes dans les différents événements de l'année 1917, et ensuite, pour ceux qui sont restés en Russie, dans l'organisation de l'administration de l'État soviétique.

3. Au sujet de l'organisation des zemstva, voir Robert Philippot, Société civile et État bureaucratique dans la Russie tsariste : les Zemstvos, Paris, Institut d'études slaves, 1991.

4. Chiffres cités par R. Philippot, op. cit., p. 114, d'après l'ouvrage de V. K. Trutovskij, Sovremennoe zemstvo (Le zemstvo contemporain), Petrograd, 1914.

5. V.R. Lejkina-Svirskaja, Intelligencija v Rossii vo vtoroj polovine XIX veka (L'intelligentsia en Russie dans la seconde moitié du XIX' ${ }^{\mathrm{e}}$ siècle), Moscou, Mysl', 1971 ; L. K. Erman, Intelligencija $v$ pervoj russkoj revoljucii (L'intelligentsia dans la première révolution russe), Moscou, Nauka, 1966. Citons également les contributions réunies dans Richard Pipes, ed., The Russian intelligentsia, New York, Columbia University Press, 1961 ; voir également Dietrich Beyrau, «Russische Intelligenzija und Revolution», Historische Zeitschrift, 252, 1991, pp. 559-586.

6. N. Frieden, Russian physicians in an era of reform and revolution, 1856-1905, Princeton, 1981 ; C. Ruane, Gender, class and the professionalization of Russian city teachers, 18601914, Pittsburgh, University of Pittsburgh Press, 1994.

7. M. Confino, art. cit., pp.415-419.

8. À ce sujet, voir notamment B. B. Veselovskij, Istorija zemstva za 40 let (Quarante ans d'histoire du zemstvo), Saint-Pétersbourg, 1909-1911, 4 vols.

9. Cf. R. Philippot, op. cit., p. 115. 
Par ses différentes caractéristiques, le groupe des statisticiens des zemstva se prête particulièrement à ce type d'approche. En effet, avec un effectif qui avait fortement grossi entre 1880 et 1914, il était devenu une des catégories les plus nombreuses des professions intellectuelles au service de ces administrations locales. En outre, assumant un rôle très proche de celui d'un expert, ses membres figuraient parmi les plus qualifiés des professionnels des zemstva. Robert E. Johnson et Alessandro Stanziani ont mis en évidence certains traits de ce groupe $^{10}$. Il reste cependant à en préciser un peu plus les formes concrètes d'expression professionnelle, sociale et politique, à reconstituer et à comprendre les logiques d'action de ces hommes, à essayer de cerner le système de valeurs qui guidait leurs comportements. Par ailleurs, les liens que ces statisticiens ont pu tisser entre eux à l'échelle nationale, au sein de leurs sociétés scientifiques et de leurs congrès professionnels, donnent à leur groupe une dimension qui semble dépasser le cadre purement local, ce qui pose alors une autre question : dans leur cas, où passait la ligne de démarcation entre le local et le national?

Nous appuierons notre analyse sur l'étude d'un exemple précis, celui des statisticiens du bureau statistique du zemstvo de Saratov ${ }^{11}$. Par son ancienneté, puisqu'il a fait partie des premiers bureaux créés au début des années 1880, par sa taille, importante, et par la continuité de son fonctionnement jusqu'en 1917, celui-ci fournit un cas approprié à une telle réflexion. Outre cela, situé dans un zemstvo à dominante libérale, il peut fournir un éclairage sur les relations entre le processus de professionnalisation des individus exerçant une activité intellectuelle au service de ces administrations locales et le mouvement libéral des zemstva entre 1890 et 1917.

Après avoir reconstitué les itinéraires qui ont conduit à Saratov les premiers responsables du bureau statistique du zemstvo, nous essaierons de comprendre le rôle joué par la configuration politique locale dans la vitalité de la production statistique de celui-ci. Dans un troisième temps, l'analyse des caractéristiques de la pratique professionnelle des statisticiens de cette province aidera à mettre en évidence les formes de leur professionnalisation, ainsi que leur mode d'insertion dans une communauté professionnelle et scientifique plus large, nationale. Enfin, l'étude des modalités de leur participation à la vie politique locale permettra de caractériser avec plus de précision la conception qu'ils avaient de leur rôle comme acteur local et l'étendue de leur action.

10. R. E. Johnson, «Liberal professionals and professional liberals : the zemstvo statisticians and their work », in Terence Emmons, Wayne S. Vucinich, The zemstvo in Russia, Cambridge, Cambridge University Press, 1982, pp. 343-363 ; A. Stanziani, L'économie en révolution - le cas russe, 1870-1930, Paris, Albin Michel, 1998 ; A. Stanziani, « La professionnalisation de la bureaucratie économique en Russie : les statisticiens de 1870 à 1914 », in Pierre Guillaume, ed., op. cit., pp. 363-378.

11. Cet article reprend en les développant certains éléments présentés dans ma thèse de doctorat: M. Mespoulet, Personnel et production du bureau statistique de la province de Saratov. Histoire d'une professionnalisation interrompue (1880-1930), Thèse de doctorat de Démographie et sciences sociales, Paris, EHESS, janvier 1999 (directeur de thèse Alain Blum). 


\section{Des hommes venus d'ailleurs}

En octroyant à des assemblées territoriales la charge d'organiser et de financer certains services obligatoires, comme la prévoyance sociale et la conservation des réserves de grains, ainsi que la responsabilité de domaines pour lesquels elles bénéficiaient d'une plus grande liberté d'action, comme la santé et l'enseignement, le Statut de 1864 a donné une impulsion décisive à la statistique régionale des zemstva en Russie ${ }^{12}$. Confrontées à la nécessité de disposer d'informations chiffrées pour guider leur action, ces nouvelles institutions d'administration locale ont dû très rapidement recruter des statisticiens pour effectuer le travail de collecte et de traitement des données nécessaires. Selon différentes sources, on estime entre 3000 et 3500 le nombre de salariés employés dans l'ensemble des bureaux statistiques des zemstva à la veille de l'année 191713. Parmi eux, plus de 1200 avaient une qualification de statisticien, contre un peu moins de 300 vingt ans plus tôt ${ }^{14}$. Placé au cœur de la production des données chiffrées pour l'administration d'un zemstvo, le statisticien était devenu un personnage central de celleci. L'étude des itinéraires suivis par les hommes du bureau statistique de Saratov va nous aider à mettre en lumière certaines caractéristiques de la formation de ce groupe de professionnels.

\section{Les chemins de l'exil intérieur}

Situation caractéristique d'une gubernija qui ne possédait pas d'université avant 1909, la plupart des statisticiens du zemstvo de Saratov vinrent d'ailleurs. Si certains d'entre eux, à l'exemple de S. A. Harizomenov ou de N. N. Černenkov, arrivèrent par choix, beaucoup d'autres furent conduits dans cette ville par les chemins de l'exil. Ainsi poursuivaient-ils une tradition entamée trente ans plus tôt par N. I. Kostomarov au sein du comité de la gubernija du Comité central de la statistique de l'État tsariste (Central'nyj statističeskij komitet - CSK). Tout

12. Rappelons que les assemblées territoriales étaient créées à deux niveaux administratifs, celui de la gubernija et celui de l'uezd, district rural. La volost', canton rural, ne disposait pas d'assemblée spécifique.

13. Voir V. Abramov, «Zemskaja statistika : organizacija i praktika » (La statistique des zemstva : organisation et pratique), Voprosy statistiki, 3, 1996, pp. 65-72; R. Philippot, op. cit., p. 115. Cet effectif comprend l'ensemble du personnel permanent des bureaux de gubernija et d'uezd : statisticiens, employés chargés du calcul des données, personnel administratif. Pour disposer d'une estimation plus précise, il conviendrait d'ajouter à ces chiffres l'effectif du personnel temporaire car des statisticiens étaient employés régulièrement avec ce statut dans les différents bureaux. Ainsi, par exemple, à Saratov en 1897 le bureau était composé de treize statisticiens permanents et trois temporaires pour une durée de six mois. Cf. S. N. Veleckij, Zemskaja statistika (La statistique des zemstva), Moscou, 1899, t. 1, p. 212. À titre de comparaison, V.R. Lejkina-Svirskaja estime à 4300 personnes l'ensemble du personnel agronomique des zemstva en 1913 (op. cit., p. 47).

14. En raison de l'absence de précision de la part des auteurs cités sur la manière dont ces chiffres ont été calculés, ceux-ci sont donnés ici à titre indicatif. 
comme Kostomarov, arrivé d'Ukraine en exil politique, ces hommes du zemstvo furent envoyés à Saratov, ou, pour certains, y trouvèrent refuge, après avoir été bannis de la ville où ils résidaient à la suite d'une condamnation pour délit politique. Celui-ci pouvait avoir pris la forme d'un activisme réel au sein d'un groupe politique clandestin, mais, fait plus fréquent, une simple dénonciation pour avoir tenu des propos contre le tsar ou la participation à une manifestation d'étudiants avaient pu faire condamner ces hommes et les engager sur les routes de l'exil intérieur. Les itinéraires politiques qui les avaient amenés à Saratov pouvaient être différents, mais, dans tous les cas, le parcours géographique effectué fut comparable pour tous. Marqué par l'errance de gubernija en gubernija à la recherche d'un emploi pour vivre, ce trajet prenait fin quand le statisticien ou l'ancien étudiant trouvait un zemstvo prêt à le recruter. Deux parcours de statisticiens du bureau de Saratov illustrent particulièrement ces chemins de l'exil intérieur.

Tout comme N. F. Annenskij avant son arrivée à Nižnij Novgorod en 188715, ou comme V. N. Grigor'ev avant son recrutement à Moscou en $1886^{16}$, V. I. Serebrjakov, futur directeur du bureau statistique du zemstvo de Saratov, mena une vie itinérante avant de pouvoir s'installer dans cette ville, en avril $1893^{17}$. Après ses débuts de statisticien au côté de V. I. Orlov, en 1881, et des postes successifs dans les bureaux des zemstva de Moscou, Kursk, Rjazan' et Orel, il fut condamné, en 1888 , pour activité politique contre l'État, ce qui interrompit son activité statistique. Il la reprend, semble-t-il, en 1890, dans le bureau du zemstvo d'Orel, d'où il part, en 1891, pour celui de Moscou, où il restera quelques mois. Contraint, comme beaucoup d'exilés politiques, à des emplois de courte durée, en 1892, il se retrouve comptable dans l'administration du zemstvo de Nižnij Novgorod ${ }^{18}$ au sein du service d'assistance aux victimes de la famine de 1891. Les premiers mois de 1893, il est employé par le comité de statistique de cette gubernija ${ }^{19}$. Ensuite, en avril de la même année, après une courte période passée à nouveau à Moscou, il est envoyé en résidence à Saratov. Placé sous surveillance policière et dénué de ressources, il est contraint de chercher un nouvel emploi ${ }^{20}$. Rapidement l'administration du zemstvo va le recruter comme comptable dans la commission de contrôle administratif, d'où il passera très vite, dès le printemps 1894, au bureau de statistique. Comme d'autres statisticiens condamnés pour délit politique, il s'installa enfin, de manière durable, quand il trouva un poste fixe dans un zemstvo. Venu de la statistique, il y revint dès que la possibilité lui en fut donnée. D'abord directeur adjoint de ce bureau de

15. À ce sujet, voir V. G. Korolenko, « Tretij element (Pamjati N. F. Annenskogo)» (Le troisième élément (En mémoire de N. F. Annenskij), Russkoe bogatstvo, 7, 1913, pp. 260-273.

16. À ce sujet, voir V. G. Mihajlovskij, «Vasilij Nikolaevič Grigor'ev. Nekrolog » (Vasilij Nikolaevič Grigor'ev. Nécrologie), Vestnik statistiki, 4-6, 1925, pp. IX-XVII.

17. GASO (Gosudarstvennyj Arhiv Saratovskoj Oblasti), fonds «Saratovskoe gubernskoe žandarmskoe upravlenie » (Direction de la gendarmerie de la gubernija de Saratov), f. 53, op. 1, d. 48 (année 1893), 1. 46.

18. GASO, f. 53, op. 1, d. 48, 11. 33, 35.

19. Il s'agit du bureau local du CSK.

20. GASO, f. 53, op. 1, d. 48, 1. 99. 
province, il en prit la direction à partir de 1904 et resta à sa tête au-delà d'Octobre 1917, quand celui-ci devint un bureau de gubernija de la nouvelle administration statistique de l'État bolchevik ${ }^{21}$.

Pour sa part, N. I. Rakitnikov ne devint statisticien qu'à son arrivée à Saratov. Il illustre cette catégorie d'hommes venus à la statistique tardivement, quand celle-ci leur a donné un emploi et un moyen de subsistance dans la ville où ils avaient été envoyés en résidence surveillée après une condamnation. Son activisme politique le mena à l'activité de statisticien. Toutefois, les chiffres n'étaient pas chose nouvelle pour lui puisqu'il était docteur en mathématiques de l'université de SaintPétersbourg. À l'âge de 24 ans, il fut envoyé en résidence surveillée, pour trois ans, dans la gubernija de Vologda, après sa condamnation pour crime d'État le 30 mars $1888^{22}$. Au bout de quelques mois, il fut autorisé à résider dans la province d'Astrahan'. Là, il fut d'abord précepteur dans une famille noble, puis surveillant de salle dans l'hôpital d'une petite ville de la gubernija. Il arriva à Saratov en août 1891. Il y vécut de leçons particulières jusqu'à son recrutement, en mai 1893, comme secrétaire dans le département de l'instruction publique du zemstvo ${ }^{23}$. Après avoir effectué quelques enquêtes statistiques dans ce service, il entra au bureau statistique du zemstvo en 1895. Il y resta en poste de manière continue jusqu'à son départ de Saratov, en 1902. Ensuite, ses différentes fonctions politiques au sein du parti socialiste révolutionnaire lui firent mener une activité statistique en pointillé. Les périodes de travail statistique à Saratov ont alterné avec ses séjours à l'étranger ou à Moscou. Il fournit un très bon exemple de ces hommes venus à la statistique par la force des choses et qui ont toujours donné la priorité à leur activité politique locale ou nationale.

La ville de Saratov vit ainsi arriver en exil un nombre non négligeable de statisticiens, dont quelques-uns ont marqué de leur empreinte l'histoire de la statistique russe et soviétique. Ce fut le cas notamment de V. M. Obuhov ${ }^{24}$, qui arriva en 1897 à la suite de son arrestation à Saint-Pétersbourg pour son appartenance à l'organisation marxiste Sojuz bor'by za osvoboždenie rabočego klassa (Union de la lutte pour la libération de la classe ouvrière). De fait, les chemins de l'exil intérieur amenèrent à Saratov des membres de différentes professions intellectuelles. Ce fut le cas

21. V. I. Serebrjakov dirigea ce bureau jusqu'à sa fermeture, en juillet 1928.

22. GASO, f. 53, op. 1, d. 63 (année 1891), 11. 6, 11, 21, 63 ; fonds « Saratovskoe gubernskoe statističeskoe bjuro » (Le bureau statistique de la gubernija de Saratov), f. R-1, op. 1, d. 233, 1. 1.

23. GASO, f. 53, op. 1, d. 63 (année 1891), 11. 13, 47, 48, 86 ; f. 5, op. 2, d. 1167, 1. 1.

24. V. M. Obuhov (1873-1945) est resté connu pour ses travaux dans le domaine de la statistique des récoltes. Après 1918, il fut un des responsables de la Direction centrale de la statistique, la CSU (Central'noe statističeskoe upravlenie). Chargé plus particulièrement des travaux méthodologiques dans le domaine de la statistique agricole, il dirigea un temps le département de la statistique des récoltes de la CSU. De 1926 à 1930, il fut à la tête de l'Institut de la méthodologie statistique. Plus tard, de 1933 à 1938, il dirigea le groupe d'étude des rendements agricoles au sein du commissariat à l'Agriculture. À son sujet, voir V. P. Kornev, Vidnye dejateli otečestvennoj statistiki, 1686-1990. Bibliografičeskij slovar' (Les acteurs éminents de la statistique russe, 1686-1990. Dictionnaire bibliographique), Moscou, Finansy i statistika, 1993, pp. 105-106. 
d'agronomes comme N. P. Oganovskij, par exemple ${ }^{25}$. Arrivèrent également des médecins, des vétérinaires, des enseignants. Dans la seconde moitié du XIX ${ }^{\mathrm{e}}$ siècle, cette ville figurait parmi celles où étaient autorisés à s'installer ceux qui revenaient d'exil de Sibérie. Cela y mena P. A. Argunov ${ }^{26}$. Arrêté à Moscou en 1886, en raison de son appartenance à l'Union générale des étudiants, association illégale, il avait été tout d'abord assigné à résidence dans la gubernija de l'Enisej27. Au printemps 1891, il en partit pour Kazan', avant de s'installer, en 1892, à Saratov.

Une autre raison explique la venue de ces hommes. S'installer dans une ville était une chose, encore fallait-il, après une condamnation, pouvoir y trouver un emploi. Le passé politique de ces nouveaux arrivants ne rebutait pas le conseil du zemstvo de Saratov. De tendance libérale, ce dernier faisait partie de ceux qui, dans les années 1890, accueillaient ce genre d'exilés qualifiés. À la recherche d'un personnel expérimenté, qu'il avait beaucoup de mal à trouver sur place, pour diriger ses différents services administratifs, il n'hésitait pas à profiter de cette opportunité pour embaucher ces intellectuels formés dans les universités d'autres villes de l'Empire. Ainsi a-t-il ouvert les portes de son administration à beaucoup d'anciens étudiants de Moscou ou de Saint-Pétersbourg.

\section{Un réseau de placement national}

En réalité, bien souvent les statisticiens n'arrivaient pas par hasard dans une ville comme Saratov. Les chemins de l'exil étaient étroitement liés aux réseaux intellectuels dans lesquels ces hommes étaient insérés à l'échelle nationale. Pendant les années 1870 et 1880 , V. I. Orlov, directeur du bureau du zemstvo de Moscou'28, supervisait un véritable système de placement des statisticiens sur l'ensemble du territoire des zemstva. Formés auprès de lui ou de ses collaborateurs les plus proches, les jeunes statisticiens étaient placés, recommandés par lui, dans les zemstva de province qui en recherchaient.

En fait, l'action de V. I. Orlov allait bien au-delà. Différents témoignages sur son rôle actif dans l'organisation des premières enquêtes et des premiers bureaux

25. N. P. Oganovskij (1874-1938) : agronome de formation, il arriva à Saratov après avoir travaillé dans différents zemstva. En 1909, il devint professeur à l'université de Saratov. Il a publié de nombreux travaux sur la question agraire et sur la stratification sociale dans les campagnes. Il était par ailleurs membre du parti socialiste révolutionnaire.

26. P. A. Argunov était beaucoup plus connu pour ses articles d'opinion dans la presse locale et nationale que pour ses travaux en statistique. Ceux-ci pourtant n'ont pas été négligeables, bien qu'occultés par son activité politique au sein du parti socialiste révolutionnaire et surtout par celle de son frère, A. A. Argunov, qui fut un des leaders nationaux de ce parti dès sa création.

27. GASO, f. 53, op. 1, d. 42 (année 1892), 11. 11, 16ob, 17.

28. V. I. Orlov (1848-1885) : après ses études à la faculté de droit de l'université de Moscou, il commença à travailler au sein de la chaire de droit public de cet établissement. En 1875, il devint directeur du bureau statistique du zemstvo de Moscou, nouvellement créé. En 1882, au côté de A. I. Čuprov, il fonda la section de statistique de la Société juridique de Moscou, qui joua un rôle essentiel pour impulser l'élaboration d'une méthodologie commune à l'ensemble des bureaux statistiques des zemstva. 
statistiques de nombreux zemstva sont restés, à l'exemple de celui qu'a livré A. F. Fortunatov dans ses souvenirs :

«L'influence de V. I. Orlov sur le développement de la statistique des zemstva a été colossale [...]. Dans quelques gubernii, V. I. Orlov a commencé lui-même les travaux de recensement des exploitations paysannes et, dans d'autres, il a été consultant [konsul'tant] dès les premiers pas de l'activité des bureaux de statistique. » 29

La présence très forte en province de cet homme de Moscou pouvait aller jusqu'à l'intervention directe comme médiateur dans le cas d'un conflit entre un statisticien et le gouverneur local au sujet de la conduite d'une enquête :

«Parmi les tournées de V. I. Orlov en province, j'ai été le témoin de son séjour à Samara. [...] Assister aux discussions diplomatiques entre Orlov et le gouverneur fut instructif pour moi. Il fallait calmer les foudres administratives prêtes à éclater sur la statistique de Samara à la suite d'une dénonciation concernant un ancien étudiant de l'Académie Petrovskij, K. E. Paprič, soupçonné d'avoir animé des conversations séditieuses avec des paysans au sujet de la question agraire. V. I. Orlov réussit à défendre le jeune collègue du bureau de Samara. $»^{30}$

Tout comme, entre autres, les bureaux de Tambov, de Kursk, de Samara ou de Voronež, celui de Saratov fut organisé, en 1882, sous l'égide de V. I. Orlov ${ }^{31}$. Ici aussi, l'influence de ce dernier fut déterminante puisque non seulement il présida aux premières heures de l'activité statistique de ce zemstvo, mais il y fut également à l'origine de la nomination des premiers directeurs de son bureau. Ancien étudiant de la faculté de droit de l'université de Moscou et membre de la Société juridique de Moscou, L.S. Ličkov ouvrit le bureau. En 1885, il fut remplacé par S. A. Harizomenov, lui-même ancien étudiant de la faculté de droit de Moscou ${ }^{32}$. L'influence de V.I. Orlov fut prolongée après sa mort par l'action d'un de ses

29. A. F. Fortunatov, «Iz vospominanij o dejateljah Moskovskoj zemskoj statistiki » (Souvenirs des grandes figures de la statistique du zemstvo de Moscou), Vestnik statistiki, 7-9, 1924, pp. 233-247 ; V. F. Karavaev, Bibliografičeskij obzor zemskoj statističeskoj i ocenočnoj literatury so vremeni učreždenija zemstv. 1864-1903gg. (Panorama bibliographique des ouvrages de statistique et d'évaluation des zemstva depuis la création des zemstva, 1864-1903), SaintPétersbourg, IVEO, 1906, 1, p. 276.

30. A. F. Fortunatov, art. cit.,p. 237.

31. V. F. Karavaev, op. cit. Le bureau de Tambov fut créé en 1880, celui de Kursk en 1882, celui de Samara en 1883 et celui de Voronež en 1884. Sur l'apport de V. I. Orlov à la structuration du réseau des bureaux statistiques des zemstva, on pourra se reporter à N. A. Kablukov, «V. I. Orlov, zemskij statistik» (V. I. Orlov, statisticien du zemstvo), Russkaja mysl', 10, 1885, pp. 121-126; et à R. A. Ejdel'man, « Russkij zemskij statistik V. I. Orlov » (Le statisticien russe du zemstvo, V. I. Orlov), in Očerki po istorii statistiki SSSR (Essais sur l'histoire de la statistique de 1'URSS), Moscou, Gosstatizdat, 1961, pp. 20-42.

32. Des éléments de la biographie de S. A. Harizomenov sont donnés un peu plus loin dans l'article. 
élèves, N. A. Kablukov ${ }^{33}$. N. N. Černenkov ${ }^{34}$, formé auprès de ce dernier au sein du bureau de statistique du zemstvo de Moscou, arriva ainsi à Saratov. Il dirigea l'activité de son bureau de statistique de 1893 à 1903.

Ainsi se constituèrent les bureaux de statistique des zemstva. Bien qu'inscrits dans une configuration institutionnelle locale, leur mode d'organisation et la conduite de leurs premières enquêtes durent beaucoup aux conceptions du travail statistique développées au sein du bureau du zemstvo de Moscou et des sociétés de statistique nationales, comme la section de statistique de la Société juridique de Moscou ou celle de la Société libre d'économie. Cette appartenance de fait à une communauté scientifique et intellectuelle nationale se doublait d'une solidarité dans l'exil. Chaque directeur de bureau d'un zemstvo arrivé en poste dans le cadre du système de placement décrit se faisait un devoir, quand cela lui était possible, d'accueillir un statisticien en exil politique à la recherche d'un emploi. Jusqu'à sa mort, V. I. Orlov s'efforça lui-même de trouver une place en province à ceux qui étaient dans ce cas. N. F. Annenskij, par exemple, fut nommé de cette manière à la tête du bureau de Kazan' en $1883^{35}$.

À Saratov, cette tradition de solidarité envers les exilés ne fut jamais démentie. D'après les rapports de la police locale, en 1902, parmi les dix membres du bureau statistique qui avaient rang de statisticien, au moins sept étaient arrivés en exil, pour la plupart dans la deuxième moitié des années $1890^{36}$. Ainsi N. N. Černenkov avaitil recruté V.I. Serebrjakov, mais aussi N. I. Rakitnikov, N. D. Rossov et

33. N. A. Kablukov (1849-1919) : ancien étudiant de la faculté de droit de Moscou, il compléta sa formation en économie en Allemagne. Revenu en Russie, il devint un des statisticiens les plus connus du bureau du zemstvo de Moscou. Formé auprès de V. I. Orlov, il le remplaça à la tête de ce bureau en 1885, après son décès. À son tour, il forma beaucoup de statisticiens des zemstva et exerça une fonction d'expert en statistique auprès de différentes administrations de zemstvo. Sa carrière d'enseignant de statistique à l'université de Moscou commença en 1900, date à laquelle il remplaça A. I. Čuprov. Il fut nommé professeur en 1903. À son sujet, voir N. A. Kablukov, «Avtobiografija » (Autobiographie), Vestnik statistiki, 8-12, 1919, Appendice, pp. 1-24.

34. Né en 1863, N. N. Černenkov commença à participer à des enquêtes statistiques en 1885 . Entré au bureau statistique du zemstvo de Moscou en 1885, il y travailla sous la direction de N. A. Kablukov, et le quitta pour celui de Saratov en 1890. Là, il fut d'abord adjoint de S. A. Harizomenov. En 1903, il partit de Saratov pour le bureau de Černigov, où il était encore en 1919. Son nom reste associé aux premiers travaux sur les différences sociales dans la paysannerie russe et à l'introduction de la notion de cycle de vie familial dans cette analyse. À ce sujet, voir N. N. Černenkov, « K harakteristike krest'janskogo hozjajstva » (Sur les caractéristiques de l'économie paysanne), Saratovskaja zemskaja nedelja, 11, 32-33, 1900. Ce texte a donné lieu ensuite à une publication séparée à Moscou en 1900, en 1905, puis à une réédition en 1918.

35. N. F. Annenskij (1843-1912) : ancien étudiant de la faculté de droit de l'université de Moscou, il fut arrêté en 1869. Après sa libération, il trouva un emploi de statisticien au ministère des Transports, à Saint-Pétersbourg, en 1873. À nouveau arrêté en 1880, il fut envoyé en exil pour trois ans en Sibérie. Là, il noua des liens durables avec V. G. Korolenko et K. A. Verner. À son retour de Sibérie, il fut introduit par V. I. Orlov auprès du zemstvo de Kazan'. À son sujet, voir notamment V. G. Korolenko, art. cit.

36. GASO, fonds «Saratovskoe gubernskoe po zemskim i gorodskim delam prisutstvie » (Prisutstvie de la gubernija de Saratov pour les affaires du zemstvo et de la ville), f. 25, op. 1, d. 1427, 11. 17-20. 
N. V. Narbekov ${ }^{37}$. Même un agronome comme K. A. Maceevič trouva un poste dans ce bureau en août $1901^{38}$. D'autres y trouvèrent un refuge temporaire. Ce fut le cas de P. A. Argunov. Alors que ses différentes condamnations politiques passées lui ôtaient le droit de bénéficier d'un poste stable dans quelque administration que ce fût, N. N. Černenkov l'embaucha avec un statut temporaire pour effectuer des enquêtes dans les campagnes.

Les premières formes de constitution de ce corps de professionnels des zemstva furent donc celles d'une organisation nationale en réseau, structurée par les liens entre les individus, mais aussi, comme nous le verrons plus loin, par les moments forts de regroupement que constituaient les congrès professionnels convoqués régulièrement. Ainsi se tissaient et se renforçaient les liens professionnels et personnels entre les hommes. Une sensibilité sociale et politique commune contribuait à cimenter un peu plus solidement encore ce réseau.

\section{Une communauté professionnelle large}

La solidarité dans l'exil débordait le cadre du seul bureau de statistique. D'autres départements de l'administration du zemstvo ont accueilli des hommes à des postes de statisticien. Certains se retrouvèrent ainsi dans le département de l'instruction publique. Tel fut le cas de N. I. Rakitnikov. De son côté, N. V. Narbekov dirigea d'abord les études statistiques du département des routes du zemstvo, puis celles du département vétérinaire. À la fin des années 1890, A. A. Argunov ${ }^{39}$, beaucoup plus connu pour son activité politique que pour son expérience en statistique, fut employé un temps comme statisticien dans ce service. Bien entendu, le département d'économie aussi employait des statisticiens. Comme d'autres services du zemstvo, il accueillait des transfuges du bureau de statistique quand celui-ci était touché par des réductions d'effectifs.

Le contexte institutionnel créé par le Statut de 1864 explique la diversité des postes qui pouvaient être offerts dans le domaine de la statistique. Cette situation était la conséquence de la responsabilité qui incombait aux zemstva dans la collecte des impôts et dans l'organisation de nombre de services à caractère économique et social. Dans les plus libéraux d'entre eux, elle était aussi la traduction des préoccupations du conseil du zemstvo en matière de progrès économique et social. Dans le domaine de l'enseignement, ceci a donné lieu, dès les années 1890, à la création de

37. Recruté en 1897 par le zemstvo de Saratov, N. V. Narbekov partit plus tard, après 1905, dans celui de Jaroslavl'. Après 1918, il devint directeur du bureau statistique de la gubernija de Jaroslavl'.

38. GASO, f. 25, op. 1, d. 1427, 11. 17-20. Proche de A. V. Čajanov, K. A. Maceevič faisait partie du groupe des « agronomes sociaux ».

39. Frère de P. A. Argunov. Né en 1866, A. A. Argunov fut un des fondateurs et des dirigeants nationaux du parti socialiste révolutionnaire. Il arriva à Saratov en 1893. Auparavant il avait passé quelques années en exil politique à Tomsk, au début des années 1880, puis avait été étudiant à l'université de Moscou à la fin des années 1880. Populiste, il fit partie des fondateurs de l'Union des socialistes révolutionnaires, créée à Saratov au milieu des années 1890. 
véritables services de statistique scolaire dans certains zemstva, par exemple dans celui de Tver' en $1893^{40}$. Témoignage de l'effort pour homogénéiser la production de ce type de données au niveau national, un congrès des zemstva sur la statistique scolaire eut lieu le 18 juin 1913 à Har'kov. Pour sa part, la statistique sanitaire connut un développement rapide dès la création des zemstva. Confrontés à l'obligation d'organiser un réseau d'infrastructures médicales, les médecins exprimèrent très vite le besoin de connaître le plus finement possible l'état sanitaire de la population de leur gubernija. Un bureau de statistique sanitaire fut créé dans chaque zemstvo. Des congrès locaux et nationaux coordonnaient les programmes d'enquêtes et les méthodes d'observation des différents bureaux. La plupart du temps les enquêtes étaient conduites par des médecins dans leur propre circonscription d'uezd. Parfois, elle étaient menées par des statisticiens. V. M. Obuhov débuta ainsi sa carrière dans le zemstvo de Voronež, avant de se spécialiser dans la statistique agricole courante à partir de 1899, après son arrivée à Saratov .

Parler des statisticiens d'un zemstvo nécessite donc de faire référence à une communauté locale beaucoup plus large que celle du seul bureau de statistique, ce qui rend par ailleurs plus difficile l'évaluation de leur nombre et peut expliquer les écarts de chiffres que l'on trouve à ce sujet dans différentes publications de cette époque. Une autre difficulté se présente quand on tente cet effort d'estimation. Comment considérer l'ensemble des médecins qui collectaient des données chiffrées pour le département de la santé publique et publiaient des études statistiques souvent fort intéressantes pour la démographie ${ }^{41}$ ? Une question similaire se pose à propos de certains enseignants du département de l'instruction publique. Tout professionnel du zemstvo ressentait le besoin de collecter des données chiffrées et de les analyser pour disposer des informations nécessaires pour guider son action. Instrument privilégié de connaissance du social, la collecte de données statistiques était, de ce fait, largement pratiquée par différents corps professionnels, à une époque où le processus de professionnalisation du métier de statisticien démarrait, mais où l'accès à la profession n'était pas encore complètement codifié.

40. Cf. V. Abramov, art. cit.

41. À Saratov, le meilleur exemple de ce genre de travaux a été fourni par les publications de N. I. Tezjakov, médecin qui dirigeait le département de la santé publique du zemstvo au début de ce siècle, et qui était par ailleurs membre de la Société Pirogov. Citons en particulier ses Materialy po izučeniju detskoj smertnosti v Saratovskoj gubernii (Matériaux pour l'étude de la mortalité infantile dans la gubernija de Saratov) qui, parus entre 1904 et 1908, ont laissé une analyse très détaillée de la situation et des causes de la mortalité infantile dans la région de Saratov entre 1899 et 1904. 


\section{Une alliance autour de la statistique}

\section{Administrateurs et statisticiens}

L'ampleur du recrutement des statisticiens a toutefois varié d'un zemstvo à l'autre. Cela a été fonction, en particulier, du poids du groupe des nobles libéraux dans l'assemblée et dans le conseil du zemstvo ${ }^{42}$. Là où ces deux instances étaient dominées par des représentants conservateurs de la noblesse foncière, les recrutements furent moins nombreux. En revanche, dans les zemstva dirigés par des nobles actifs dans le mouvement libéral, non seulement les statisticiens étaient nettement plus nombreux, mais ils étaient également plus écoutés. À ce dernier groupe ont appartenu notamment les zemstva de Tver', de Moscou, de Voronež, de Černigov, de Saratov aussi ${ }^{43}$. Ainsi peut-on distinguer deux formes institutionnelles différentes du contexte d'embauche des statisticiens selon la configuration politique locale du zemstvo. Dans un cas, peu armés techniquement pour gérer les domaines d'intervention dévolus aux zemstva par le Statut de 1864, les administrateurs représentants de la noblesse locale au conseil du zemstvo n'eurent pas d'autre solution que de faire appel à un personnel spécialisé dans ces différentes questions. Dans l'autre cas, comme N. M. Pirumova l'a mis en évidence ${ }^{44}$, quand les nobles libéraux étaient en position majoritaire pour prendre les décisions au sein de l'assemblée et du conseil du zemstvo, ils saisirent l'occasion offerte par le Statut pour organiser une auto-administration locale qui soit un réel pouvoir de résistance face à l'État tsariste. Ceci a été le cas du zemstvo de Saratov, même si l'influence de ces hommes a pu être plus ou moins forte selon les périodes ${ }^{45}$.

À partir des années 1890, la gubernija de Saratov pouvait s'enorgueillir de quelques figures nationales du mouvement libéral des zemstva. Le plus connu d'entre eux est resté N. N. L'vov. Né en 1865, fils d'un gros propriétaire foncier de l'uezd de Balašov, celui-ci avait fait ses études à la faculté de droit de l'université de Moscou. Issu de la noblesse héréditaire, il fut maréchal de la noblesse de l'uezd de Balašov de 1893 à $1899^{46}$. Il était en outre membre de l'assemblée du zemstvo de cet uezd et de celle de la gubernija de Saratov. En juillet 1899, il devint président du conseil du zemstvo. Il assuma cette fonction jusqu'en mars 1902, date à laquelle il

42. Une assemblée délibérante était élue pour trois ans à chaque niveau territorial, uezd et gubernija. L'assemblée de la gubernija désignait un conseil du zemstvo, qui était un organe exécutif composé d'un président et de deux à six membres.

43. Cf. N. M. Pirumova, Zemskoe liberal'noe dviženie (Le mouvement libéral des zemstva), Moscou, Nauka, 1977.

44. Ibid.

45. Ibid.; voir également Očerki istorii Saratovskogo Povolž'ja (Essais sur l'histoire de la région de Saratov), Saratov, Saratovskij gosudarstvennyj universitet, t. 2, 1995 ; V. V. Širokova, Očerki istorii obščestvennogo dviženija v Saratovskoj gubernii v poreformennyj period (Essais d'histoire du mouvement social dans la gubernija de Saratov après la période des réformes), Saratov, 1976.

46. E. K. Maksimov et al., Istorija Saratovskogo kraja (Histoire de la région de Saratov), Saratov, Detskaja kniga, 1996, pp. 243-245. 
décida de quitter cette charge pour se consacrer à l'organisation d'un parti libéral national. Il prit une part active dans les réunions du groupe illégal Besed ${ }^{47}$, fut un des fondateurs, au côté de P. B. Struve, de la revue libérale Osvoboždenie, dont le premier numéro parut à Stuttgart en 1902. Il fit partie, en juillet 1903, de ceux qui fondèrent l'Union de libération, organisation politique illégale. Créée par les libéraux des zemstva, celle-ci rassemblait également des universitaires et des membres des professions intellectuelles extérieures aux zemstva, des hommes d'opinion politique modérée ou socialiste, à l'exception des sociaux démocrates ${ }^{48}$. Des statisticiens en faisaient partie. Parmi eux, deux populistes, N.F. Annenskij et A. V. Pešehonov, figuraient, à côté de N. N. L'vov, dans les dix membres du comité exécutif de cette organisation ${ }^{49}$. «L'alliance libérale-radicale », décrite par Thomas S. Fallows dans son étude sur la vie politique de la région de la Volga à cette époque ${ }^{50}$, n'était que le reflet local d'une dynamique politique plus large, impulsée par une partie des libéraux à l'échelle nationale. N. N. L'vov prit également une part active à l'élaboration et à la rédaction des résolutions prises par le premier congrès national des représentants des zemstva qui se tint à Saint-Pétersbourg en novembre $1904{ }^{51}$. Il participa de manière tout aussi active, notamment dans la gubernija de Saratov, à la « campagne des banquets » qui démarra en novembre 1904. L'année suivante, il fut élu membre du comité exécutif du tout nouveau parti constitutionnel démocrate, le parti cadet, dont il était par ailleurs l'un des fondateurs ${ }^{52}$. En 1906, il fut élu député à la première Douma d'État. Il le fut à nouveau à la troisième et à la quatrième, après avoir quitté le parti cadet et fondé un groupe plus modéré53.

La démarche politique de N. N. L'vov est caractéristique de celle des libéraux progressistes de l'époque. Avant d'être un homme de parti, il fut un homme de

47. Ce groupe s'était constitué à partir des rencontres informelles entre différents libéraux au cours de congrès régionaux des zemstva. Sur l'histoire et l'activité de ce groupe, on pourra se reporter notamment à N. M. Pirumova, op. cit., et à Viktor Léontovitch, Histoire du libéralisme en Russie, Paris, Fayard, 1986.

48. Sur l'histoire de l'Union de libération, voir notamment V. Léontovitch, op. cit.; George Fisher, Russian liberalism, Cambridge, MA, Harvard University Press, 1958 ; Richard Pipes, Struve : Liberal on the left, 1870-1905, Cambridge, MA, Harvard University Press, 1970 ; Shmuel Galai, The liberation movement in Russia, 1900-1905, Cambridge, Cambridge University Press, 1973.

49. Le comité exécutif était composé de cinq membres issus de la noblesse des zemstva et de cinq représentants des professions intellectuelles extérieures au zemstvo. I. I. Petrunkevič, P. D. Dolgorukov, D. I. Sahovskoj, N. N. L'vov et N. Kovalevskij formaient le premier groupe, N. F. Annenskij, V. Ja. Bogučarskij, S. N. Prokopovič, A. V. Pešehonov et S. N. Bulgakov constituaient le second. À ce sujet, voir G. Fisher, op. cit., pp. 139-152. Voir aussi I. I. Petrunkevič, Iz zapisok obščestvennogo dejatelja (Mémoires d'un homme public), Berlin, 1934.

50. T. S. Fallows, Forging the Zemstvo movement : Liberalism and radicalism on the Volga, 1890-1905, Thèse PhD, Harvard University, 1981.

51. Ce congrès est souvent présenté comme « le prologue à la révolution de 1905 ».

52. Le parti cadet fut fondé en octobre 1905.

53. Après 1917, N. N. L'vov prit part à la guerre civile dans les rangs de l'armée blanche, puis, en 1920, émigra en France. Installé à Paris, il collabora au quotidien Vozroždenie, avant de s'éteindre en 1944, à l'âge de 79 ans. 
réseau qui s'efforça de structurer un mouvement politique à partir de rencontres informelles et d'organisations plus formelles. Ainsi était née Beseda. Ce groupe s'était formé petit à petit, entre 1899 et 1904, à partir des rencontres entre quelques libéraux au sein de congrès des zemstva ou au domicile privé de certains d'entre eux. Il rassemblait des hommes progressistes de tendances politiques diverses, mais qui devaient tous remplir ou avoir rempli une fonction élective ou professionnelle dans l'administration d'un zemstvo ou d'une ville. D'après Robert Philippot, il n'existait «que par un faisceau de relations personnelles $»^{54}$.

Au début du siècle, parmi les autres membres du parti cadet de l'assemblée du zemstvo de la gubernija de Saratov, on comptait A. D. Jumatov, qui fut président du conseil du zemstvo de 1903 à 1906. Citons aussi S. A. Kotljarevskij, un des autres fondateurs de l'Union de libération et, par ailleurs, professeur à l'université de Moscou. Figuraient également A. M. Maslennikov et le comte D. A. Olsuf'ev, président du conseil du zemstvo quelques mois en 1902 et 1903, membre également du groupe Beseda ${ }^{55}$. Tous ces hommes étaient diplômés des universités de Moscou ou de Saint-Pétersbourg. Cette proximité intellectuelle a vraisemblablement favorisé une collaboration réelle entre statisticiens et administrateurs du zemstvo, parfois même soudée par des liens de solidarité qui survécurent à la révolution d'Octobre. Ainsi retrouvera-t-on plus tard, en janvier 1919, dans le bureau de la gubernija de la nouvelle administration statistique de l'État bolchevik, des anciens nobles libéraux qui avaient joué un rôle important au sein du conseil du zemstvo.

Parmi ceux-ci, A. D. Jumatov lui-même figurait encore, en janvier 1920, sur la liste du personnel de la section de la statistique agricole du bureau de la gubernija ${ }^{56}$. Pour sa part, I. I. Panfilov, qui avait été, à partir de 1907, membre du conseil du zemstvo chargé des études statistiques, était directeur du bureau statistique de l'uezd de Saratov à sa création, en janvier $1919^{57}$. Expression d'une forme de solidarité locale sur un fond de communauté d'idées, les anciens statisticiens du zemstvo, devenus à leur tour administrateurs, accueillirent parmi eux certains de ceux qui les avaient recrutés bien des années plus tôt, quand eux-mêmes cherchaient un refuge institutionnel. Renversement des rôles lié au retournement de l'histoire, les statisticiens du bureau de la gubernija de l'État bolchevik recrutèrent leurs anciens administrateurs pour les mêmes raisons que ceux-ci les avaient embauchés eux-mêmes par le passé : à la recherche d'un refuge, ces anciens acteurs du zemstvo leur offrirent des compétences et une qualification que les responsables du bureau de statistique, confrontés à un besoin urgent et élevé en personnel, avaient du mal à trouver sur place.

54. R. Philippot, op. cit., p. 121.

55. Cf. N. M. Pirumova, op. cit., pp. 205-211. D. A. Olsuf'ev était en outre responsable de la section de Saratov de la Croix Rouge.

56. GASO, f. R-1, op. 1, d. 64,1. 20.

57. GASO, f. R-1, op. 1, d. 64,1. 117. 
L'exemple de Saratov offre ainsi l'opportunité de mieux comprendre sur quels fondements reposait concrètement l'alliance entre le «deuxième » et le «troisième » élément souvent évoquée à propos de différents zemstva. Pour Thomas S. Fallows, la vitalité du mouvement du zemstvo dans la province de Saratov s'explique par la forme particulière qu'y a prise cette coopération qu'il a baptisée « alliance libérale-radicale ${ }^{58}$. D'après Donald J. Raleigh, de la seconde moitié des années 1890 à la révolution de 1905, « les révolutionnaires de Saratov maintinrent des relations cordiales avec les cercles libéraux locaux »59. Thomas S. Fallows insiste notamment sur le fait que cette gubernija se caractérisait par « une tradition de coopération entre modérés et extrémistes, qui devint manifeste dans les liens personnels et politiques qui unissaient les nobles libéraux du zemstvo et les docteurs, statisticiens et enseignants radicaux, et aussi les autres 'intellectuels démocrates' employés par l'institution démocratique ${ }^{60}$. Ainsi, par exemple, N. N. L'vov apporta-t-il son soutien financier à la parution du journal social démocrate Iskra. De son côté, en 1905, A. A. Tokarskij, futur leader du parti cadet à Saratov, organisait fréquemment des réunions de discussion auxquelles il invitait des membres de mouvements et de partis politiques plus radicaux.

Le cas de Saratov montre également que, contrairement à ce que l'on peut lire parfois, dans cette province-ci, cette alliance a survécu à l'année 1905. Si, comme ailleurs, la révolution de 1905 a mis fin aux formes d'expression antérieures du dialogue entre nobles libéraux et représentants du « troisième » élément, ici, elle a marqué un point d'orgue plutôt qu'un coup d'arrêt. Même si des divergences d'opinion pouvaient opposer les uns et les autres, notamment au sujet de la question agraire, face aux impératifs de la gestion locale des affaires publiques, l' « alliance libérale-radicale » avait laissé des traces durables. Donald J. Raleigh en a décrit les survivances pendant l'année 1917. En ce qui concerne plus particulièrement l'administration statistique, on en retrouvait encore des manifestions au-delà d'Octobre 1917.

Au niveau national, tout comme au niveau local, la richesse de la production statistique russe et le caractère novateur de beaucoup de ses travaux et de ses méthodes dans les années 1880-1917 ont été stimulés par la rencontre entre des statisticiens mobilisés par la recherche d'outils et d'études apportant une meilleure connaissance du social et de l'économie et des administrateurs libéraux soucieux de progrès économique et social ainsi que de changement politique. Au-delà des différences d'opinion et d'appartenance politique, et sans effacer celles-ci, les zemstva ont servi de cadre institutionnel à cette rencontre. Le foisonnement des enquêtes statistiques à leur sujet et des questionnements méthodologiques qui les ont accompagnées en a été le résultat.

58. T. S. Fallows, op. cit.

59. D. J. Raleigh, Revolution on the Volga, 1917 in Saratov, Ithaca, Cornell University Press, 1986, p. 51.

60. T. S. Fallows, cité par D. J. Raleigh, ibid. 


\section{Une alliance locale favorable à la production statistique}

Dans la gubernija de Saratov, les liens entre administrateurs libéraux et statisticiens s'étaient soudés non seulement dans le cadre du travail courant de la gestion administrative du zemstvo au sens strict, mais aussi vraisemblablement sur le terrain, au cours des enquêtes effectuées, dans le cadre d'une pratique d'observation commune. Ainsi des nobles du conseil et de l'assemblée du zemstvo, amateurs d'études statistiques, participèrent-ils à des opérations d'enquête sur l'agriculture. En outre, certains d'entre eux étaient correspondants ${ }^{61}$ du bureau statistique pour la collecte des données de la statistique courante agricole. À la fin du XIX ${ }^{\mathrm{e}}$ siècle, ces nobles étaient en quelque sorte les héritiers de ceux des années 1860-1870 qui, au sein du comité de la statistique de la gubernija, avaient réalisé les premières grosses études de la province de Saratov dans la tradition de la statistique allemande ${ }^{62}$. Toutefois, l'esprit des administrateurs du zemstvo au tournant de la fin du $\mathrm{XIX}^{\mathrm{e}}$ siècle et du début du $\mathrm{XX}^{\mathrm{e}}$ était différent de celui de leurs devanciers. Soucieux, tout comme eux, de progrès économique et social, ils s'en différenciaient néanmoins par leurs aspirations politiques. Alors que leurs prédécesseurs restaient respectueux du pouvoir tsariste, N. N. L'vov et ses collègues libéraux réclamaient l'instauration d'un régime constitutionnel et parlementaire.

Cependant, malgré leur proximité intellectuelle, à Saratov comme dans les autres zemstva, l'alliance entre nobles libéraux et statisticiens ne fut pas sans nuages. Ici aussi, à certaines périodes, des menaces ont pesé sur l'existence même du bureau statistique. Elles se sont exprimées au rythme des rapports de forces politiques établis au sein de l'assemblée et du conseil du zemstvo, mais également entre assemblée et conseil. En 1904, dans son rapport de gouverneur, Stolypin notait que la répartition entre nobles libéraux et nobles modérés ou conservateurs, au sein de l'assemblée du zemstvo, était équilibrée en nombre ${ }^{63}$. Cela semble avoir caractérisé l'ensemble de la période 1880-1917. Toutefois, les conservateurs se firent entendre plus fortement de la fin des années 1880 à la fin des années 1890, ainsi qu'au cours de la période qui a suivi la révolution de 1905. Ceci mérite néanmoins d'être nuancé. En effet, la présence, de 1906 à 1917, d'un octobriste, K. N. Grimm, à la tête du conseil du zemstvo montre que, même si les conservateurs étaient plus écoutés après 1905, de fait, ce sont plutôt les libéraux modérés qui gouvernaient ${ }^{64}$.

61. Les correspondants de la statistique agricole courante étaient volontaires et bénévoles. Deux fois par an en général, ils transmettaient au bureau statistique des informations sur l'état des terres, des semences et des récoltes agricoles.

62. M. Mespoulet, op. cit., chap. 1-2.

63. Stolypin a été gouverneur de Saratov du printemps 1903 au début de l'année 1906. Ses rapports écrits sur la situation dans cette province sont conservés aux Archives historiques d'État à Saint-Pétersbourg (RGIA), dans le fonds 1984. Cf. R. Philippot, « Stolypin gouverneur de Saratov », in Russes, Slaves et Soviétiques, Pages d'histoire offertes à Roger Portal, Paris, Institut d'études slaves, 1992, pp. 225-233.

64. En 1917, K. N. Grimm fut nommé commissaire de la gubernija par le Gouvernement Provisoire, en remplacement de l'ancien gouverneur 
Cette situation explique peut-être que, après 1905, le bureau de statistique ait continué à bénéficier d'un soutien réel de la part du conseil du zemstvo ${ }^{65}$.

En fait, à plusieurs reprises entre 1882 et 1909, le bureau ne dut sa survie qu'au soutien du conseil. Ainsi, en 1887, un désaccord opposa l'assemblée et le conseil au sujet du financement de son activité, jugé trop élevé par la première. La commission statistique de l'assemblée proposa de le fermer, ce qui fut fait formellement. En réalité, cela ne fut pas une réelle fermeture, dans le sens où les travaux statistiques continuèrent à être effectués avec un effectif de statisticiens réduit. Ceux-ci continuaient à être dirigés par $\mathrm{S}$. A. Harizomenov, et l'équipe tout entière dépendait directement du président du conseil. Ainsi fut trouvée une solution pour maintenir l'activité du groupe des statisticiens tout en respectant formellement la décision de l'assemblée. Ce scénario s'est répété à la fin de l'année $1892^{66}$. Bien que menacé de fermeture à d'autres reprises par la suite, chaque fois le bureau de statistique ne subit en fait que des réductions d'effectifs qui affectèrent principalement les travaux de statistique agricole courante ${ }^{67}$. En fin de compte, le dialogue entre le directeur du bureau et le conseil du zemstvo fut toujours maintenu et la continuité du travail statistique préservée. Les sympathies libérales de N. N. Černenkov ont été vraisemblablement un facteur favorable à cette situation pendant tout le temps qu'il a dirigé le bureau, de 1893 à 1903. En particulier, le bureau put rester ouvert après les émeutes paysannes de 1902, malgré les très fortes pressions du ministère de l'Intérieur pour pousser à sa fermeture. L'effectif de son personnel fut néanmoins réduit ${ }^{68}$.

À son tour, son successeur, V. I. Serebrjakov, a su nouer avec les libéraux du conseil des relations de travail durables, qui ont reposé dans certains cas sur des liens personnels. Les statisticiens de ce zemstvo purent ainsi bénéficier d'un appui réel de la part du conseil, notamment entre 1899 et 1905 . Comme dans les autres provinces russes, cette alliance fut toutefois bousculée par l'année 1905, d'autant plus que les soutiens les plus forts et les plus écoutés, comme N. N. L'vov et S. A. Kotljarevskij, avaient quitté Saratov pour se consacrer à leur activité politique nationale ${ }^{69}$. Cependant, cette fois encore, le bureau statistique ne fut pas fermé. Il fut seulement restructuré et, comme en témoignent ses publications, son activité fut recentrée essentiellement sur les statistiques agricoles courantes et sur les travaux d'estimation des biens fonciers et immobiliers ${ }^{70}$.

65. Cf. S. N. Veleckij, op. cit., pp. 126-129.

66. Ibid.

67. Cf. V.I. Serebrjakov, «K voprosu o postanovke tekuščej statistiki v zemskih učreždenijah » (À propos de la situation de la statistique courante dans les administrations des zemstva), Trudy podsekcii statistiki XII S' 'ezda russkih estestvoispytatelej i vračej [Černigov], 1912 , pp. 479-491.

68. GASO, f. 25, op. 1, d. 1427.

69. Au sujet des conséquences des événements de l'année 1905 sur les relations entre le « deuxième » et le «troisième » élément au sein des administrations des zemstva, voir notamment R. Philippot, op. cit., pp. 126-129.

70. Cf. V. N. Grigor'ev, Predmetnyj ukazatel' materialov v zemsko-statističeskih trudah s 1860-h godov po $1917 \mathrm{~g}$. (Table analytique par matière des travaux statistiques des zemstva des années 1860 à 1917), Moscou, 1926-1927, 2 vols. 
En réalité, cette situation ne dura pas longtemps, les besoins en informations chiffrées de l'administration du zemstvo furent plus forts. En 1909, le bureau avait retrouvé un effectif permanent de onze personnes et un volant de personnel temporaire de treize personnes ${ }^{71}$. En fait, à partir de janvier 1907, il avait trouvé un allié et un soutien de poids en la personne de I. I. Panfilov, nouveau membre du conseil du zemstvo $^{72}$. En janvier 1908, celui-ci fut à l'origine du vote d'une résolution de l'assemblée affirmant la nécessité de conserver un bureau statistique comme « organe permanent » au sein de l'administration du zemstvo ${ }^{73}$. Un peu plus tard, s'appuyant sur ce texte, en septembre 1909, il présenta un projet de développement de l'activité statistique et du bureau du zemstvo de Saratov qui aurait pu être rédigé par un statisticien lui-même ${ }^{74}$. Peut-être d'ailleurs ce texte a-t-il été écrit à deux voix, la sienne et celle de V. I. Serebrjakov, alors directeur du bureau. Après avoir réaffirmé le principe du maintien d'un bureau permanent, il en fixait les tâches. Il insistait en particulier sur le fait que, devant le caractère incomplet et peu précis du travail des administrations de volost', seule une telle structure pouvait assurer correctement les tâches de collecte des données de statistique courante dans tous les domaines de la responsabilité du zemstvo. L'activité du bureau s'en trouva relancée. Le recrutement de statisticiens d'uezd qualifiés reprit, à raison d'un par uezd, et leurs tâches furent définies par un texte réglementaire. Le réseau des correspondants fut renforcé. Le principe de la convocation d'au moins deux congrès de statisticiens de la gubernija par an fut énoncé. Dans la droite ligne des recommandations des congrès internationaux de statistique du $\mathrm{XIX}^{\mathrm{e}}$ siècle, la constitution d'un conseil de la statistique de la gubernija fut proposée.

En fait, au-delà de la réussite de la collaboration entre le directeur du bureau et l'administrateur, une fois de plus, c'est le principe de réalité qui s'imposa pour réactiver l'alliance entre libéraux du zemstvo et statisticiens. La perspective de voir transférer de l'État aux zemstva la charge de la gestion de l'approvisionnement alimentaire de la gubernija joua un rôle décisif :

«Il faut s'attendre à ce que, dans un avenir très proche, l'approvisionnement alimentaire, qui est actuellement de la compétence du gouvernement, soit transféré entièrement aux administrations des zemstva. Rien que cela - c'est une affaire très complexe - va imposer aux administrations des zemstva la nécessité absolue de disposer, en particulier, d'informations fiables et tenues à jour sur les perspectives de récolte pour une année donnée, sur les résultats de la moisson, sur l'ampleur des besoins attendus dans le domaine de l'aide alimentaire, etc. $\gg^{75}$

71. GASO, fonds «Saratovskaja gubernskaja zemskaja uprava » (Le conseil du zemstvo de la gubernija de Saratov), f. 5, op. 1, d. 2633,1.61.

72. GASO, f. 5, op. 2, d. 1093, 11. 3-4.

73. GASO, f. 5 , op. 1, d. 2633,1. 48.

74. GASO, f. 5, op. 1, d. 2633, 11. 48-70 : « Doklad Iv. Iv. Panfilova o reorganizacii tekuščej statistiki » (Exposé de I. I. Panfilov sur la réorganisation de la statistique courante).

75. GASO, f. 5, op. 1, d. $2633,1.53$ 


\section{Un dialogue entre administrateurs et experts}

$\mathrm{S}$. N. Veleckij et B. B. Veselovskij ${ }^{76}$ l'ont souligné : de manière générale, la collaboration entre administrateurs et statisticiens des zemstva ne fut pas sans heurts, même si cela a pu varier selon les zemstva et selon les périodes. Alessandro Stanziani a décrit les conflits qui ont pu éclater entre les uns et les autres dans certaines provinces ${ }^{77}$. L'exemple de Kursk éclaire les formes d'opposition qui pouvaient naître dans un zemstvo dirigé par des conservateurs et qui pouvaient aboutir à la fermeture effective du bureau statistique ${ }^{78}$. Le zemstvo de Saratov illustre, au contraire, le cas des zemstva qui ne connurent pas une telle situation, même quand des voix s'élevèrent au sein de l'assemblée pour réclamer la suppression du bureau. En revanche, ce dernier point peut expliquer les variations d'intensité de la production statistique locale. En effet, le travail statistique n'était jamais aussi actif que quand le bureau bénéficiait d'un réel soutien de la part du conseil. Quand les libéraux étaient à la direction des affaires de la gubernija, la production statistique du zemstvo était d'autant plus riche.

Administrateurs libéraux et statisticiens avaient souvent été formés dans les mêmes universités, principalement à Moscou et à Saint-Pétersbourg, dans les facultés de droit, en particulier. Cette formation commune venait sceller une proximité d'idées, contribuait à constituer une communauté intellectuelle locale. Dans certains cas, les trajectoires suivies par les statisticiens étaient comparables à celles de certains administrateurs, parfois même ils étaient issus de leurs rangs. Le zemstvo de Černigov est souvent cité comme exemple. Au début des années 1890, V. E. Varzar était membre de l'assemblée du zemstvo en même temps qu'il en dirigeait le bureau statistique ${ }^{79}$. A. A. Rusov était également membre de cette assemblée quand, en 1899 , il prit la direction de ce bureau ${ }^{80}$. Tel était aussi le cas de F. A. Ščerbina dans le zemstvo de Voronež. Pendant près de vingt ans, de 1884 à 1903, il fut membre de son assemblée tout en dirigeant son bureau statistique.

L'alliance entre le «deuxième » et le «troisième » élément du zemstvo fut d'autant plus facile à réaliser que ces hommes étaient issus de milieux sociaux identiques ou proches, partageaient les mêmes références intellectuelles et les mêmes aspirations politiques. Tous réclamaient un régime constitutionnel et parlementaire. Les diverses commissions de travail de l'assemblée du zemstvo furent des espaces privilégiés du dialogue entre statisticiens et administrateurs. Alliés de fait par un même comportement d'opposition à l'égard du pouvoir tsariste et par une même

76. S. N. Veleckij, op. cit.; B. B. Veselovskij, op. cit.

77. A. Stanziani, « Statisticiens, zemstva et État dans la Russie des années $1880 »$, Cahiers du Monde russe et soviétique, 4, 1991,pp. 445-468.

78. À ce sujet, voir également B. B. Veselovskij, op. cit.; I. P. Belokonskij, Zemskoe dviženie (Le mouvement des zemstva), Saint-Pétersbourg, 1914.

79. Cf. N. M. Pirumova, op. cit., pp. 278-279. V. E. Varzar dirigea le bureau statistique de Černigov de 1875 à 1894, puis partit travailler au ministère du Commerce et de l'Industrie.

80. Ibid. 
aspiration au changement, ces hommes trouvèrent dans ces commissions de gestion locale un champ d'action concret commun pour mettre en œuvre leurs projets de construction d'une autre forme d'économie et de société, même si des différences d'analyse et d'opinion pouvaient les opposer sur certains points.

Un compte rendu des discussions de la session ordinaire de l'assemblée du zemstvo de la gubernija de Saratov de 1903, consacrées aux questions soulevées par le calcul des primes d'assurance contre l'incendie, laisse percevoir la forme du dialogue entre administrateurs libéraux et statisticiens à cette époque, éclaire la manière dont un statisticien pouvait remplir sa fonction d'expert du zemstvo, la façon également dont il articulait son rôle professionnel et sa propre philosophie sociale et politique ${ }^{81}$. Dans l'extrait suivant, le directeur du bureau statistique, N. N. Černenkov, présente les résultats d'une enquête réalisée par son équipe au sujet de la situation financière du système d'assurance obligatoire contre l'incendie dans les campagnes ${ }^{82}$ et répond aux questions des conseillers du zemstvo, qui doivent décider des mesures susceptibles d'en résorber le déficit :

« À la question de N. N. L'vov sur la raison de cette différence, à savoir que le taux de sinistres augmente et le taux de couverture du risque diminue, le rapporteur, N. N. Černenkov, indique que le taux de sinistres ne change pas sur une période de dix ans, mais que, sur quinze ans, il est un peu plus élevé dans la dernière période. La variation du taux de couverture du risque ne peut pas coïncider avec le taux de sinistres, elle évolue en fonction 1) de la diminution de la destruction occasionnée par les incendies, 2) de l'estimation plus sûre des dégâts des incendies, 3) de la réglementation des estimations par les assurances, c'est-à-dire de toute la partie administrative du dossier, et 4) d'une répartition plus adéquate, dans l'ensemble, des sommes couvrant les risques entre les localités plus ou moins exposées et les types de bâtiments [...]. »

Cette dernière remarque n'était pas anodine car elle remettait en cause un principe de base du fonctionnement du système d'assurance contre l'incendie des zemstva. La loi du 7 avril 1864 obligeait ces institutions à fixer une valeur de remplacement des biens détruits forfaitaire pour l'ensemble d'un district, ce qui entraînait des inégalités entre assurés selon le risque réel d'incendie de leurs biens, par exemple le matériau de construction des bâtiments ${ }^{83}$. La réaction de $\mathrm{N}$. N. L'vov témoigne d'une prise en compte réelle par l'administrateur du zemstvo des conclusions du statisticien expert :

« N. N. L'vov estime qu'il est démontré dans l'exposé que le système en usage est allé trop loin, qu'il a été financé aux frais de la population la plus pauvre,

81. Voir « Hronika Saratovskogo zemstva» (Chronique du zemstvo de Saratov), Saratovskaja zemskaja nedelja, 2, février 1903, section « Zemskij otdel », pp. 20-25.

82. Le Statut de 1864 avait confié aux zemstva la gestion du système d'assurance mutuelle contre l'incendie dans les campagnes. Cette assurance était obligatoire et ne concernait que les seules communautés paysannes. Â ce sujet, voir R. Philippot, op. cit., pp. 86-87.

83. Ibid. 
qu'il n'a même pas donné de résultats du point de vue d'une diminution du risque d'incendie, c'est pourquoi il est indispensable de le modifier et d'augmenter les tarifs pour toutes les catégories d'assurés. Cependant il est nécessaire de considérer le nouveau système avec circonspection car il va conduire à des arriérés et à un refus de l'assurance ; pendant quelques années, les recettes vont être freinées et elles ne seront pas suffisantes pour couvrir la dette. »

Il fut décidé de fixer plusieurs taux de cotisation en répartissant les villages en sept catégories selon le risque d'incendie, mais également d'augmenter pour tous le taux de base des versements. La réaction de N. N. Černenkov à ce sujet témoigne de la manière dont, dans son rôle d'expert, le statisticien pouvait être partagé entre son souci de servir la rigueur de la gestion des affaires publiques du zemstvo et sa préoccupation de ne pas alourdir les cotisations des paysans les plus pauvres :

« N. N. Černenkov indique qu'il préférerait reporter d'un an l'introduction du nouveau tarif, cependant la situation du zemstvo de Saratov dans le domaine de l'assurance est critique. Si l'on conserve l'ancien système, c'est seulement dans le cas des années favorables qu'il n'y aura pas de pertes, et il y en aura lors des mauvaises années. »

Expert chargé d'éclairer les décisions relatives à la gestion du zemstvo, le statisticien s'efforçait de trouver une voie moyenne entre son projet social et la raison économique, cherchant un compromis entre la contrainte budgétaire et la lutte contre la pauvreté et les inégalités. Telle fut l'attitude des statisticiens dans leurs différents domaines d'intervention. Au service de l'administration de leur zemstvo, ils s'appuyaient sur les résultats de leurs enquêtes pour fournir à ceux qui dirigeaient les informations susceptibles d'éclairer leurs décisions, sans taire pour autant leurs propres préoccupations de progrès social.

\section{Une alliance nationale}

Après les tensions consécutives aux événements de l'année 1905, la Première Guerre mondiale scella à nouveau l'alliance entre administrateurs libéraux et statisticiens des zemstva au niveau national, en particulier au sein de l'Union des zemstva. Avec l'entrée en guerre de la Russie en août 1914, une Union panrusse des zemstva (Vserossijskij zemskij sojuz) « pour l'aide aux soldats malades et blessés » se constitua sur le modèle de celle de la guerre russo-japonaise ${ }^{84}$. Créée à l'initiative du zemstvo de Moscou, très vite elle réunit presque tous les zemstva. Seuls le zemstvo de Kursk et quelques autres du sud-ouest restèrent en dehors. L'Union se dota très rapidement d'une administration très structurée, à la fois en province et à l'échelon national, qui allait la faire apparaître bientôt, face à la carence de l'État 
tsariste, comme une véritable administration de substitution. Parallèlement, d'anciennes aspirations se firent entendre à nouveau, en particulier celles relatives à l'instauration d'un État constitutionnel et démocratique.

De manière générale, les statisticiens furent, aux côtés des agronomes, parmi les fonctionnaires des zemstva les plus actifs au sein des différents organismes économiques nationaux créés pendant la Première Guerre mondiale ${ }^{85}$. De 1915 à 1917, l'un d'entre eux, V. G. Groman ${ }^{86}$, fut à la tête du bureau économique de l'Union des villes. D'autres se retrouvèrent dans la section d'économie du comité principal de l'Union des zemstva. Les statisticiens de Saratov ne furent pas en reste puisque, en 1915, le directeur du bureau du zemstvo lui-même, V. I. Serebrjakov, était délégué du conseil du zemstvo au comité principal de l'Union ${ }^{87}$. Son parcours symbolise à bien des égards la position intellectuelle qui semble avoir été celle de beaucoup de ses collègues des zemstva. Cadre de l'administration de son zemstvo et, par ailleurs, intellectuel inséré dans des réseaux nationaux, V. I. Serebrjakov trouva dans l'Union des zemstva un espace d'expression à l'intersection de ses préoccupations de gestion locale et de ses aspirations à un nouveau régime politique pour le pays.

En rendant nécessaire une coordination nationale des représentants des zemstva au sein de différents organismes, la Première Guerre mondiale provoqua en quelque sorte une mobilisation des zemstva vers la gestion de l'État. Il en est resté des traces dans l'organisation de la production des données statistiques en Russie. Ainsi la création d'un bureau central de statistique fut-elle demandée à l'occasion du congrès des statisticiens réuni du 5 au 7 mars 1916 par le comité principal de l'Union pour examiner le projet de recensement agricole demandé par le Conseil national de l'approvisionnement du ministère de l'Agriculture ${ }^{88}$. Les opérations d'organisation devaient être confiées aux zemstva. De fait, pendant cette période, deux recensements nationaux, l'un sur l'approvisionnement des villes, l'autre sur l'agriculture, firent basculer la statistique des zemstva d'une statistique régionale vers une statistique nationale, dans le sens où, dans les deux cas, la production des données fut organisée à l'échelle de l'ensemble du territoire russe.

À Saratov, le recensement de l'approvisionnement des villes ${ }^{89}$ réunit les statisticiens du zemstvo, des coopératives et des établissements d'enseignement supérieur

85. Au sujet des différents organismes économiques créés pendant la Première Guerre mondiale en Russie, voir notamment A. Stanziani, «Spécialistes, bureaucrates et paysans. Les approvisionnements agricoles pendant la Première Guerre mondiale, 1914-1917 », Cahiers du Monde russe, 1-2, 1995, pp. 71-94.

86. V. G. Groman (1874-1940) : économiste et statisticien ; après avoir commencé sa carrière comme statisticien des zemstva, il travailla pour la Direction centrale de la statistique (CSU) à partir de l'année 1919 et dans le bureau de la conjoncture du Gosplan à partir de 1923. En 1926, il était à la fois membre du présidium du Gosplan et membre du collège de la CSU. Évincé de son travail en 1929, il fut arrêté en 1930, puis condamné, en mars 1931, dans le cadre du procès des mencheviks. Il fut réhabilité après sa mort.

87. GASO, f. 5, op. 2, d. 1243,1. 23.

88. Le Conseil national à l'approvisionnement avait été créé le 17 août 1915 à l'initiative du ministère de l'Agriculture.

89. Ce recensement fut également impulsé par le Conseil national à l'approvisionnement. 
de la ville, en fait la plus grosse partie de la communauté statistique locale. Il fut organisé et dirigé par deux hommes arrivés au début de la guerre, A. A. Rybnikov ${ }^{90}$, proche de A. V. Čajanov, et I. N. Kokšajskij ${ }^{91}$, économiste du mouvement coopératif. Conçu sur le modèle du recensement de la ville de Moscou de 1912, il respectait les principes d'organisation préconisés par les congrès internationaux de statistique du XIX ${ }^{\mathrm{e}}$ siècle, ce que souligne I. N. Kokšajskij dans son introduction au rapport sur les données préliminaires :

« Les questionnaires du recensement ont été empruntés presque complètement à celui de Moscou, en raison du fait qu'il s'agit des questionnaires les plus élaborés et les plus vérifiés dont on dispose, sur la base déjà de l'expérience de nombreux recensements. Par leur nature, ces questionnaires ne présentent pas quoi que ce soit d'original puisqu'ils ont été construits entièrement à partir de l'expérience des grandes villes de l'Europe de l'Ouest et des travaux des congrès internationaux de statistique. ${ }^{92}$

Ainsi, à la fin du mois de janvier 1916, un recensement était-il conduit à Saratov, comme dans d'autres villes russes, sur la base de questionnaires standardisés, déjà utilisés dans d'autres villes européennes.

L'organisation du recensement agricole russe de l'été 1916 fut confiée aux bureaux statistiques des zemstva sur décision du ministère de l'Agriculture. Sa préparation donna lieu à différents congrès nationaux, qui fournirent aux statisticiens des zemstva l'occasion longtemps espérée d'organiser et de conduire une collecte des données agricoles uniforme dans l'ensemble des provinces russes. Ce fut une étape décisive dans le passage de la statistique régionale des zemstva à une statistique nationale. Beaucoup des statisticiens qui assumèrent la charge de ce recensement organisèrent par la suite les premiers recensements de l'administration statistique bolchevique. De manière générale, l'Union des zemstva offrit une scène nationale à la dimension des aspirations des acteurs locaux qu'étaient les statisticiens des zemstva. L'organisation en réseau de leur communauté professionnelle trouva dans l'Union un champ d'intervention à sa mesure, à la croisée des ambitions scientifiques et des aspirations sociales et politiques de ses membres.

Champ d'expérimentation du projet libéral des uns et du projet social et scientifique des autres, les zemstva furent un terrain de rencontre et de collaboration entre

90. A. A. Rybnikov (1877-1940) : ancien élève de l'Académie d'agriculture Petrovskij, économiste et membre actif du mouvement coopératif, il s'installa à Saratov au début de la Première Guerre mondiale. Auparavant, en 1913, il avait déjà effectué une enquête sur l'industrie artisanale de la gubernija de Saratov pour le compte du zemstvo. Il fut professeur d'économie à l'université de Saratov de 1914 à 1922, année où il quitta définitivement cette ville pour Moscou. Il fut arrêté à la fin des années 30 et fut victime de la répression.

91. I. N. Kokšajskij était un économiste du mouvement coopératif. Lui aussi arriva à Saratov au début de la Première Guerre mondiale. Il en repartit en 1922.

92. I. N. Kokšajskij, Predvaritel'nye dannye perepisi naselenija goroda Saratova i ego prigorodov, proizvedennoj v 1916 godu (Données préliminaires du recensement de la population de la ville de Saratov et de ses faubourgs, réalisé en 1916), Saratov, izd. Saratovskogo gubernskogo zemstva, 1917. 
des hommes aux sensibilités politiques proches ou différentes, selon les cas, mais qui partageaient tous une même opposition au régime autocratique. Ils furent aussi en quelque sorte un espace d'intersection entre deux réseaux reliant des hommes qui, bien qu'ancrés dans les préoccupations de gestion locale, n'en concevaient pas moins leur activité dans le cadre d'un système de références politiques ou professionnelles plus large. À partir de la fin du XIX $\mathrm{X}^{\mathrm{e}}$ siècle, les nobles libéraux administrateurs des zemstva formaient un réseau cimenté par un projet politique constitutionnel et parlementaire. À côté, l'organisation en réseau des statisticiens reposait beaucoup plus sur des préoccupations professionnelles. Cela n'empêchait pas des croisements entre ces deux réseaux dans le cadre d'espaces communs. C'était le cas en particulier des congrès professionnels, qui étaient aussi des lieux de débat politique, et qui furent un élément de structuration très actif du mouvement libéral des zemstva93 ${ }^{3}$. C'était aussi le cas, après sa création, des réunions du parti cadet, dans lequel on a pu compter bon nombre de statisticiens, N. A. Kablukov et A. F. Fortunatov par exemple. Certains, comme A. A. Kaufman et N. N. Černenkov, participèrent à l'élaboration du programme agraire de ce parti ${ }^{94}$.

Cette configuration à la fois institutionnelle et politique de l'action des zemstva est un élément essentiel pour comprendre le dynamisme de la statistique des zemstva russes entre les années 1880 et 1917. Elle constitue une caractéristique spécifique du développement foisonnant de cette forme de statistique régionale en Russie à cette époque, tout en l'inscrivant dans un espace intellectuel national. Dans un tel contexte, les statisticiens mirent leur pratique professionnelle au service du progrès social. Leur projet professionnel devint l'expression active de leur projet social, de leurs aspirations au changement politique. Dans cette optique, le mode d'organisation de ce corps de professionnels doit être analysé à la confluence de l'expression des exigences scientifiques de ses membres et des formes institutionnelles et politiques prises par le système de gestion et d'administration des zemstva.

\section{Une pratique professionnelle locale insérée dans un réseau scientifique national}

\section{L'enjeu de la qualification}

À partir des années 1880, l'organisation des structures institutionnelles de la production des données statistiques des zemstva est allée de pair avec la transformation du groupe des statisticiens en un corps de professionnels. Au premier rang des règles et des usages de celui-ci a figuré la qualification. En cela, dans bien des cas, les préoccupations des statisticiens ont rencontré celles de leurs administrateurs. Au sein du conseil du zemstvo de Saratov, un accord a, semble-t-il, toujours

93. À ce sujet, voir N. M. Pirumova, op. cit.; S. Galai, op. cit.

94. Au sujet du rôle joué par A. A. Kaufman, voir «Avtobiografija (Autobiographie), Vestnik statistiki, 5-8, 1921,pp. 260-274. 
existé au sujet de la nécessité de recruter un personnel qualifié pour le bureau de statistique. Le niveau d'études des premiers statisticiens engagés en juillet 1882 en témoigne ${ }^{95}$. Embauchés pour effectuer les opérations d'enquête des premiers recensements par ménage dans les districts ruraux, la plupart d'entre eux étaient soit anciens étudiants de l'Académie d'agriculture Petrovskij de Moscou, soit diplômés de la faculté de droit ou de la faculté de physique et de mathématiques de l'université de Moscou. Ceux qui ne sortaient pas de l'université ou d'une académie étaient anciens élèves d'un séminaire de la région de la Volga. En fait, on le voit, dès le début des années 1880, un très petit nombre de filières de recrutement peut être distingué, et la plupart des statisticiens venaient de l'extérieur de la province de Saratov.

Entre 1882 et 1917, les différents directeurs du bureau statistique du zemstvo étaient, presque tous, issus de l'enseignement supérieur. Seul N. N. Černenkov fit exception puisqu'il n'avait pas poursuivi ses études au-delà de la fin de sa scolarité dans un gymnase (gimnazija) ${ }^{96}$. En revanche, L. S. Ličkov et S. A. Harizomenov étaient diplômés de la faculté de droit de l'université de Moscou. De son côté, V.I. Serebrjakov sortait de l'Institut technique commercial de Moscou ${ }^{97}$. Les directeurs adjoints également avaient, presque tous, suivi des études supérieures. C'était le cas de N. I. Rakitnikov, docteur en mathématiques de l'université de Saint-Pétersbourg, de V. M. Obuhov, diplômé de mathématiques de l'université de Moscou, et de I. I. Gil'genberg, qui n'eut toutefois pas le temps de terminer sa formation à l'Institut polytechnique de Saint-Pétersbourg avant d'être renvoyé pour agitation politique ${ }^{98}$. Seul $\mathrm{A}$. F. Milovzorov échappa à cette règle quand il fut nommé adjoint en 1916, après vingt-deux ans de service au sein du bureau. Son ancienneté et son niveau de responsabilité dans l'organisation et la conduite des études d'estimation foncière compensèrent l'absence de formation universitaire après la fin de ses études dans un gymnase ${ }^{99}$.

D'après A. V. Voronežcevi00, au début de l'année 1902, les dix-neuf employés permanents du bureau de statistique se distinguaient des autres fonctionnaires du zemstvo de Saratov par un niveau de formation plus élevé. Six d'entre eux, soit

95. GASO, fonds «Kanceljarija Saratovskogo gubernatora » (Chancellerie du gouverneur de Saratov), f. 1, op. 1, d. 3644, 11. 1-187: «Perepiska s Saratovskoj gubernskoj zemskoj upravoj » (Correspondance avec le conseil du zemstvo de la gubernija de Saratov).

96. RGAE (Rossijskij Gosudarstvennyj Arhiv Ekonomiki), fonds « Central'noe statističeskoe upravlenie » (Direction centrale de la statistique), f. 1562, op. 306, d. 65.

97. Cet institut devint, en 1906, 1'Institut de commerce de Moscou. En 1912, il acquit le statut d'un établissement d'enseignement supérieur à part entière. Son enseignement se caractérisait par une large place accordée aux cours de statistique.

98. Cf. son dossier individuel de la gendarmerie de la gubernija de Saratov, GASO, f. 53, op. 1 (année 1892), d. 21,1.4.

99. GASO, f. R-1, op. 1, d. 233,1. 2.

100. A. V. Voronežcev, Saratovskoe zemstvo nakanune i v period pervoj rossijskoj revoljucii, 1900-1907 gg. (Le zemstvo de Saratov à la veille et pendant la période de la première révolution russe, 1900-1907), Thèse de candidat d'histoire, Université de Saratov, Saratov, 1993, p. 44 . 
31,6\%, avaient terminé leurs études supérieures. Seulement deux, soit 10,5\%, ne possédaient qu'un niveau de fin d'école primaire. Tous les autres, soit 57,9\%, avaient suivi des études secondaires. Ce profil d'ensemble était conforme à celui de la plupart des bureaux des zemstva101.

Saratov offre en outre l'exemple type d'un bureau de statistique dans lequel le niveau de formation élevé semble avoir été directement lié à la fonction de terre d'accueil de cette province. Les responsables du bureau des années 1890 et 1900 étaient à l'image d'autres statisticiens qui dirigeaient d'autres bureaux de zemstvo. Anciens étudiants de Moscou ou de Saint-Pétersbourg pour la plupart d'entre eux, tous ces hommes constituaient une élite intellectuelle des zemstva soudée à l'échelle du pays par tout un réseau d'interconnaissance structuré autour des statisticiens des années 1880 et de leurs disciples, et dont les membres, formés aux mêmes sources, partageaient un même système de références intellectuelles et éthiques qui dépassait le cadre local d'un seul zemstvo. En fournissant aux bureaux des zemstva la possibilité d'engager des statisticiens plus qualifiés que le personnel qui aurait pu être trouvé sur place, où bien souvent il n'y avait pas d'université, les chemins de l'exil contribuèrent ainsi à former des collectifs de travail dans lesquels le niveau de formation moyen était plus élevé que dans d'autres services de l'administration d'un zemstvo, et qui, en outre, étaient unis par une même culture professionnelle et scientifique.

\section{Une hiérarchie des qualifications}

Cette politique de recrutement d'un personnel qualifié s'est accompagnée, dès les années 1890 , d'une spécialisation des membres du bureau de Saratov dans les différentes opérations du travail statistique. À l'organisation des tâches des années 1880 sur le modèle de l'apprentissage du métier par des disciples auprès d'un maître a succédé, dans la deuxième moitié des années 1890 mais surtout à partir de la loi de 1899 qui donna au bureau plus de moyens et plus d'hommes, une organisation plus hiérarchisée sur la base des responsabilités exercées et de la qualification acquise. Ainsi, en 1902, sur un effectif de dix-neuf personnes, dix statisticiens et un agronome forment les cadres du bureau ${ }^{102}$. Le personnel administratif est composé d'un comptable et d'un secrétaire. Le reste de l'effectif correspond aux agents recenseurs et aux employés affectés au calcul des données ${ }^{103}$. La direction du bureau est assurée par quatre personnes, le directeur, N. N. Černenkov, ses deux adjoints, V. I. Serebrjakov et N. I. Rakitnikov, et V. M. Obuhov, directeur de la section de la statistique courante agricole. Parmi les autres statisticiens, une distinction est faite

101. Cf. V. Abramov, art. cit., p. 71.

102. In A. V. Voronežcev, op. cit.

103. Il s'agit des sčetčiki. Le terme sčetčik désignait l'employé qui était affecté aux opérations techniques du calcul des données, l'équivalent du chiffreur aujourd'hui, mais aussi celui qui recopiait les données et les mettait en tableaux village par village. 
entre les statisticiens organisateurs, comme A. F. Milovzorov, qui assument une fonction d'organisation et d'encadrement des opérations d'enquête sur le terrain, et ceux, en général les plus jeunes, récemment arrivés ou diplômés seulement de l'enseignement secondaire, qui effectuent ces opérations.

Après la réduction du personnel imposée au bureau en 1905, sa réorganisation s'est traduite par une hiérarchie plus forte des qualifications. En 1909, la grille de rémunération annuelle était fixée de la manière suivante ${ }^{104}$ :

$\begin{array}{lr}\text { Directeur du bureau } & 2400 \text { roubles } \\ \text { Statisticien } & 1200 \text { roubles } \\ \text { Secrétaire } & 900 \text { roubles } \\ \text { Agent recenseur } & 720 \text { roubles } \\ \text { Employé au calcul } & 520 \text { roubles }\end{array}$

La hiérarchie des qualifications et des rémunérations reposait sur les critères conjugués de l'ancienneté, de l'expérience acquise en statistique et du niveau de formation. Des éléments de structuration d'une profession étaient donc déjà en place au début du $\mathrm{XX}^{\mathrm{e}}$ siècle à Saratov. Il est à noter par ailleurs que, dès cette période, les nouveaux statisticiens embauchés seront toujours des diplômés de l'enseignement supérieur, même quand il s'agira de recruter des statisticiens d'uezd.

Le bureau de statistique s'affirma comme une entité institutionnelle au sein de l'administration du zemstvo en même temps qu'il affina sa structuration autour de fonctions et de tâches bien différenciées. Institutionnalisation et professionnalisation ont été indissociables. L'augmentation du nombre d'enquêtes à effectuer ainsi que la lourdeur de l'organisation des recensements par ménage d'une part, des études d'estimation foncière et immobilière d'autre part, ont exigé une différenciation plus stricte des rôles et des fonctions de chacun. En cela la situation du bureau de Saratov reflétait celle de l'ensemble des bureaux des zemstva. Devant répondre à une forte demande d'enquêtes de la part des administrations locales, progressivement ces bureaux organisèrent leur personnel en un véritable corps de professionnels de la statistique dont les règles de travail, de recrutement et de promotion furent harmonisées au sein des sociétés et des congrès de statistique nationaux.

Ces règles et usages s'imposaient au niveau local. En particulier, ce groupe professionnel eut très vite ses propres filières de formation et de recrutement, communes à l'ensemble des zemstva. À la veille de 1917, seules quelques institutions de formation fournissaient l'essentiel des statisticiens des zemstva. Il s'agissait de la faculté d'économie et de droit de l'université de Moscou, des instituts de commerce de Moscou et de Kiev, de la faculté d'économie de l'Institut polytechnique de Saint-Pétersbourg, et de l'Académie d'agriculture Petrovskij ${ }^{105}$. À partir de 1907, le bureau du zemstvo de Saratov recruta beaucoup d'anciens étudiants de l'Institut de commerce de Moscou. Diplômé lui-même de cet établissement, V. I. Serebrjakov, devenu directeur du bureau à partir de 1904, embauchait

104. GASO, f. 5, op. 1, d. 2633,1. 61.

105. Pour plus de détails sur ces différents établissements d'enseignement supérieur, cf. V. R. Lejkina-Svirskaja, op. cit., chap. 1. 
d'anciens étudiants de cet institut dans lequel un enseignement théorique et pratique de la statistique était dispensé, à cette époque, par des hommes aussi connus que A.F. Fortunatov et V. I. Anisimov ${ }^{106}$. Dans les années 1910, ce n'étaient plus les chemins de l'exil politique qui menaient au bureau statistique du zemstvo de Saratov mais ceux du diplôme et de la qualification.

\section{Une figure nationale de la statistique des zemstva}

La production statistique d'un zemstvo a été d'autant plus riche que la demande institutionnelle et les préoccupations scientifiques des statisticiens ont pu coexister. Dans un tel contexte, certains de ces hommes ont acquis une notoriété nationale à partir d'un ancrage local de leurs travaux. Experts au service de leur zemstvo, ils n'en poursuivaient pas moins une réflexion scientifique nourrie par les questionnements qui traversaient l'ensemble de la communauté des statisticiens russes. À Saratov, tel fut le cas, par exemple, de S. A. Harizomenov.

Appartenant à la première génération des statisticiens des zemstva, cet homme illustre particulièrement cette catégorie de statisticiens qui, alliant pragmatisme social et questionnement scientifique, ont choisi de construire leur pratique de la statistique à partir de l'observation empirique des faits économiques et sociaux et à partir de l'enquête sur le terrain effectuée par les statisticiens eux-mêmes auprès de la population. Son introduction au recueil de synthèse des recensements par ménage de la gubernija de Saratov révèle une réelle sensibilité à l'analyse de la situation d'enquête ${ }^{107}$. En témoigne notamment l'attention particulière qu'il portait aux procédures à mettre en œuvre pour contrôler les déclarations des personnes interrogées. Ceci pouvait concerner, par exemple, les personnes susceptibles de taire des informations pour des raisons fiscales :

«L'enquête préalable a une énorme importance pour l'enregistrement des propriétaires de manufacture, qui sont fortement enclins à dissimuler leurs activités de production par crainte de l'imposition. Bien que les indications du scribe du village ne soient pas complètes, elles peuvent néanmoins servir de moyen de contrôle pour l'estimation du niveau d'exactitude des réponses des paysans. »108

106. V. I. Anisimov (1875-1920) : fils d'un statisticien, il fit ses études à l'Institut de commerce Aleksandrovskij et à l'Institut d'agronomie de Novo-Aleksandr. Il travailla comme statisticien dans les zemstva de Har'kov et de Vladimir et comme agronome dans ceux de Kursk et de Voronež. Socialiste populaire, il fut par ailleurs membre actif du mouvement coopératif. De 1904 à 1918, il enseigna la statistique à l'Institut de commerce de Moscou. Il enseignait également à l'université populaire Šanjavskij et aux cours Golicyn. En 1912, il fut nommé vice-président de la Société de statistique Čuprov, nouvellement créée. Il mourut du typhus en mai 1920 .

107. S. A. Harizomenov, Svod statističeskih svedenij po Saratovskoj gubernii (Recueil d'informations statistiques sur la gubernija de Saratov), Saratov, izd. Saratovskogo gubernskogo zemstva, 1888.

108. Ibid., p. 19. 
Il pouvait y avoir d'autres problèmes, dus plus simplement à la complexité du système du partage des terres dans la commune rurale. Devant la difficulté à obtenir des informations précises sur la composition des ménages, S. A. Harizomenov donnait les conseils suivants :

« D'un autre côté, des dvory qui ont été partagés il y a bien longtemps en deux, trois exploitations continuent à être comptés comme un seul ensemble. De très nombreuses exploitations de personnes habitant seules, de soldats, de veuves et, en particulier, de personnes vivant de longue date de manière séparée, ne figurent pas du tout sur la liste des ménages. [...] Dans un gros village, il ne faut pas du tout procéder au recensement sans une liste préparée à l'avance. »109

Le parcours intellectuel et politique de S. A. Harizomenov éclaire ses choix de statisticien. Né en 1854 dans une famille de la noblesse foncière de la gubernija de Vladimir, il fit ses études à la faculté de droit de l'université de Moscou ${ }^{110}$. L'année où il les termina, en 1876, il devint membre du groupe populiste Zemlja $i$ volja. À partir de l'été 1877, il prit une part active à l'installation de colonies populistes dans les campagnes de la province de Saratov, dans laquelle il arriva en compagnie, entre autres, de G. V. Plehanov et O. V. Aptekman ${ }^{111}$. En habits de colporteur, il fut de ceux qui partirent faire de l'agitation dans les campagnes de cette gubernija ${ }^{112}$. Ensuite, avec l'aide de nobles libéraux locaux, il trouva une place d'instituteur dans un village. Au congrès de Voronež de 1879, il adhéra à l'organisation Černyj peredel, issue de la scission de Zemlja $i$ volja.

Quand il débuta son activité statistique à Vladimir, au début des années 1880, il avait abandonné l'action politique. Ses travaux portent néanmoins l'empreinte d'une connaissance des campagnes et d'une pratique de l'observation de la vie des paysans développées au cours de ses années populistes. Son rôle à la tête du bureau statistique de Saratov, de 1885 à 1892, a orienté de manière décisive les enquêtes de ce zemstvo. Il en a défini à la fois les thèmes et les méthodes de travail. Il s'est attaché, en outre, à s'entourer d'hommes expérimentés et formés au travail statistique. En particulier, il fit venir N. N. Černenkov auprès de lui. D'après A. A. Kaufman et S. N. Veleckij ${ }^{113}$, sous son impulsion, les travaux du bureau de Saratov ont figuré parmi les plus novateurs de l'époque en Russie, en particulier

\section{Ibid.}

110. Les informations biographiques concernant S. A. Harizomenov proviennent de différentes sources: Enciklopedičeskij slovar' (Dictionnaire encyclopédique) F. A. Brokgauz, I. A. Efron, Saint-Pétersbourg, 1903, t. 37, p. 73.; Bol'šaja sovetskaja enciklopedija (Grande encyclopédie soviétique), Moscou, édition de 1957 ; CSU RSFSR, 50 let sovetskoj statistiki v Saratovskoj oblasti (50 ans de statistique soviétique dans la région de Saratov), Saratov, Gosizdat, 1968,p. 42 ; V. P. Kornev, op. cit, p. 165.

111. Očerki istorii Saratovskogo Povolž’ja, op. cit, 1995, pp. 254-261.

112. Sur cet épisode, cf. Franco Venturi, Les intellectuels, le peuple et la révolution : histoire du populisme russe au XIXe siècle, Paris, Gallimard, 1972, t. 2, pp. 935-943.

113. A. A. Kaufman, Teorija i metody statistiki (Théorie et méthodes de la statistique), Moscou, izd. I. D. Sytina, 1912 ; S. N. Veleckij, op. cit.. 
dans le domaine de la méthodologie des recensements par ménage et de la construction des tableaux combinés (kombinacionnye tablicy), tableaux croisés à plusieurs variables.

Le travail statistique ne mit pas fin à l'engagement social de S. A. Harizomenov. Ainsi n'hésita-t-il pas à interrompre sa vie professionnelle pour se consacrer, de 1892 à 1898, à une forme d'expérimentation économique et sociale dans la gestion de la propriété agricole qu'il possédait dans la gubernija de Saratov ${ }^{114}$. Membre et secrétaire du conseil de la section locale de la Société d'agriculture russe, il s'efforça, en effet, de mettre en œuvre de nouvelles techniques agricoles ainsi que de nouvelles pratiques de gestion sociale de la main-d'œuvre sur sa propre exploitation. Peu de traces sont restées de cet épisode peu connu de sa vie. Pendant cette période, il ne rompit pas pour autant ses liens avec ses collègues statisticiens du bureau du zemstvo et participa à l'édition de certains recueils des recensements par ménage. En 1893, il prit une part active à l'organisation du premier congrès des exploitants agricoles des sept gubernii du sud-est de la Russie ${ }^{115}$. Observateur de l'économique et du social, il semble qu'il s'attacha également à en être un inventeur à son propre niveau.

En 1898, il reprit son activité professionnelle au poste de directeur du bureau statistique de la gubernija de Tula. En 1901, il prit la tête de celui de Tver'. Il demeura dans cette ville jusqu'à son décès, en 1917. Outre ses écrits en statistique, il a laissé de nombreux articles à caractère économique dans les revues nationales Russkaja mysl' et Moskovskij juridičeskij vestnik, mais aussi dans des périodiques de Saratov. Membre actif de la commission scientifique des archives de Saratov dès sa création, en 1886, il participait à ses travaux et, à ce titre, écrivit notamment l'article «Description de Saratov » inséré dans l'édition de 1899 du Dictionnaire encyclopédique Brokgauz ${ }^{116}$. Ces différentes activités témoignent de la continuité de son insertion dans les réseaux intellectuels nationaux auxquels il n'a jamais cessé d'appartenir après son arrivée dans la province de Saratov.

\section{Pratique de l'enquête et socialisation professionnelle}

La conduite des recensements par ménage offre un bon exemple du caractère original des formes de l'apprentissage du travail d'enquête dans les bureaux statistiques des zemstva. La participation aux opérations d'enquête était un moment d'acquisition des savoirs et des savoir-faire, mais aussi des normes et des valeurs d'une profession. Réalisés dans le cadre d'expéditions organisées sur les lieux mêmes des enquêtes, ces recensements étaient effectués uezd par uezd par une équipe de deux à quatre statisticiens. Un ou deux hommes expérimentés étaient accompagnés par un ou deux autres qui, tout en se formant au travail d'enquête,

114. Enciklopedičeskij slovar' ..., op. cit.

115. Ibid.

116. S. A. Harizomenov, « Opisanie Saratova », in ibid., t. 38, 1899, pp. 409-420. 
assumaient la tâche d'enregistrement des données collectées sur les formulaires d'enquête. D'après S. A. Harizomenov, « le simple enregistrement mécanique des données sur les fiches du ménage » exigeait deux mois d'apprentissage sous la direction d'un statisticien expérimenté117. Cette formation des plus jeunes auprès des plus anciens était avant tout une école de la rigueur, rigueur de la méthode qui se traduisait par l'exigence de la durée de l'apprentissage sur le terrain. Dans son texte d'introduction au recueil de synthèse des premiers recensements par ménage de la gubernija de Saratov, S. A. Harizomenov justifiait la rigueur de l'apprentissage de la méthode d'enquête de la manière suivante :

« La troisième cause des réponses incorrectes tient à l'enquêteur lui-même, à son savoir-faire dans la conduite d'un recensement. Ce serait une grossière erreur de penser que l'enregistrement des réponses est un travail mécanique qui n'exige ni progrès, ni connaissances. Un statisticien doit être solidement familiarisé avec le système de dépouillement des données et avec l'objectif final de l'enquête auquel est destinée chaque colonne du questionnaire'118. S'il ne comprend pas le but et l'importance d'une question, il aura toujours une attitude peu réfléchie vis-à-vis de cette question et se contentera de réponses non précises et sujettes à caution. Beaucoup de questions posées aux paysans les font douter de leur utilité, ce qu'ils avouent sans façon. L'enquêteur qui ne connaît pas le but et le sens d'une question non seulement n'insistera pas pour obtenir des réponses précises, mais encore partagera, de manière involontaire, le doute des paysans à propos de la question posée. ${ }^{119}$

De telles remarques dépassent les simples conseils techniques de base donnés à un enquêteur. On perçoit combien cet apprentissage formait tout autant à la technique du questionnement qu'à une préparation à la situation même de l'enquête et à la compréhension de la relation enquêteur-enquêté. On comprend également pourquoi cette formation par la pratique était conçue comme l'indispensable parcours initiatique de tout statisticien débutant. Dans certains cas, elle pouvait déjà avoir été incluse dans ses études. Il en était ainsi à l'Institut de commerce de Moscou. Son département d'économie prévoyait, dans le cadre des deux dernières années de formation, un apprentissage pratique complémentaire de l'enseignement théorique. Les stages pratiques étaient effectués soit dans des bureaux statistiques des zemstva, soit dans celui de la ville de Moscou, auprès de V. N. Grigor'ev'120. Ainsi, quand le bureau de Saratov recruta V. K. Novinskij à la sortie de cet institut, en 1912, celui-ci avait déjà acquis une expérience pratique au sein du bureau de la ville

117. S. A. Harizomenov, Svod..., op. cit., pp. 28-29.

118. La présentation des premiers questionnaires des recensements par ménage consistait en un système de tableaux récapitulatifs dans les cases et les colonnes desquels étaient portées les différentes informations collectées.

119. S. A. Harizomenov, Svod..., op. cit., p. 29.

120. V. N. Grigor'ev (1852-1925) fait partie de la génération fondatrice de la statistique des zemstva. À la tête du bureau de statistique de la ville de Moscou de 1886 à 1917, il fut un de ceux qui formèrent la plus grosse partie des statisticiens russes des années 1885-1917. 
de Moscou $^{121}$. Après avoir fait ses premières armes sur le terrain comme agent recenseur, il avait été ensuite adjoint du chef des responsables de circonscription du recensement de 1912 de la ville de Moscou ${ }^{122}$.

\section{Un compagnonnage en statistique}

Si l'apprentissage de la méthodologie des enquêtes exigeait la durée, les opérations de collecte demandaient également du temps. Lors des premiers recensements par ménage, recenser l'ensemble des exploitations agricoles et de la population d'un uezd prenait trois à quatre mois, à raison de deux à trois jours par village. Cela donnait le temps à l'apprenti statisticien d'apprendre à collecter lui-même les données sous l'oeil d'un maître. Champ d'expérimentation de nouvelles méthodes, les zemstva ont offert ainsi un vaste terrain d'application et de formation.

En outre, ces expéditions obligeaient maîtres et apprentis à résider ensemble sur place, dans un uezd, pendant plusieurs mois. La proximité ainsi créée dans le travail et dans la vie quotidienne contribuait à tisser des liens serrés et durables entre les membres de l'équipe chargée d'une enquête. Différents témoignages sont restés de cette formation sur le terrain à la pratique de l'enquête et à ses difficultés, ainsi que des nombreuses discussions de travail, mais aussi politiques, qui animaient les soirées des statisticiens ${ }^{123}$. Situation propice à la circulation des idées, ce mode de résidence sur les lieux mêmes de l'enquête favorisait également un mode d'observation de la réalité sociale in situ. Cette forme de socialisation professionnelle conçue sur le modèle du compagnonnage était commune à l'ensemble des zemstva.

Cette formation par la pratique de toute une communauté professionnelle contribua à unifier et cimenter l'ethos professionnel de ses membres. En ce sens, ceux-ci étaient statisticiens des zemstva bien plus que d'un zemstvo. Dans les années 1880 et 1890 , le parcours d'apprentissage qui menait le jeune statisticien d'une gubernija à une autre lui faisait découvrir des terrains et des savoir-faire différents. Formés par V. I. Orlov, N. A. Kablukov, A. F. Fortunatov ou leurs disciples, les statisticiens des zemstva ont ainsi construit progressivement tout un réseau d'hommes sensibilisés aux mêmes questionnements et aux mêmes approches, pratiquant les mêmes méthodes, partageant les mêmes préoccupations scientifiques. Au cours de son périple professionnel à travers le pays, l'apprenti statisticien croisait les collègues, les maîtres ou les disciples des uns et des autres. Un jeune statisticien n'allait pas simplement travailler dans tel bureau d'un zemstvo, il partait plutôt apprendre auprès d'un individu, en général le directeur ou l'un de ses

121. Dossier personnel de V. K. Novinskij conservé dans les archives de l'université d'État de Saratov et GASO, f. R-1, op. 1, d. 233,1. 1 .

122. Ce recensement a servi de modèle par la suite à d'autres recensements de villes russes, dont celui de la ville de Saratov en 1916, comme cela a déjà été précisé.

123. Voir notamment A. F. Fortunatov, art. cit. 
adjoints. À cet égard, l'exemple des trajets suivis par la première génération des statisticiens de Saratov est éclairant.

L. S. Ličkov fut recruté par le conseil du zemstvo de Saratov, en 1882, sur les conseils de V. I. Orlov. Membre lui-même de la Société juridique de Moscou, il avait d'abord travaillé à Rjazan', au côté de V. N. Grigor'ev. Pour sa part, ancien étudiant de la faculté de droit de l'université de Moscou, S. A. Harizomenov avait vraisemblablement bénéficié de l'enseignement de A. I. Čuprov ${ }^{124}$ et rencontré N. A. Kablukov. Il fit ses premières armes en statistique en 1883 dans le zemstvo de Vladimir, pour partir ensuite, en 1884-1885, travailler dans le bureau du zemstvo de Tauride, qui venait d'ouvrir sous la direction de K. A. Verner, ancien adjoint de V. I. Orlov à Moscou ${ }^{125}$.

Les débuts de statisticien de V. I. Serebrjakov furent guidés par V. I. Orlov luimême, qui l'engagea dans le bureau du zemstvo de Moscou à la fin de ses études à l'Institut technique commercial de Moscou, en 1881. Là, le jeune débutant travailla auprès de V. I. Orlov et de K. A. Verner. Sous leur direction, il participa d'abord aux travaux d'estimation sur les manufactures et le usines des gubernii de Moscou et de Rjazan' ${ }^{126}$, puis, à partir de septembre 1882, aux études de statistique économique conduites par V. I. Orlov dans le zemstvo de Kursk. Ensuite, sa période d'apprentissage terminée, il fut recruté comme statisticien dans le bureau d'Orel.

Statisticiens d'un zemstvo de la Basse Volga, les hommes de Saratov n'en étaient pas moins insérés, on le voit, dans un réseau professionnel plus large, structuré à l'échelle nationale par ses pratiques de compagnonnage. De ce point de vue, dès les années 1880, la statistique d'un zemstvo était bien plus qu'une statistique régionale. Elle était un élément d'un ensemble plus vaste en train de se construire à l'échelle du pays tout entier, l'expression d'une communauté scientifique qui avait ses propres questionnements, ses objets d'étude et ses méthodes d'observation. Celles-ci étaient exposées et discutées régulièrement au sein de congrès et de sociétés de statistique.

124. A. I. Čuprov (1842-1908) : statisticien russe considéré comme le père spirituel de la statistique des zemstva. Professeur d'économie politique et de statistique à l'université de Moscou jusqu'en 1900, il a formé beaucoup de statisticiens des zemstva, dont N. A. Kablukov, qui lui succéda à l'université. Fondateur de la section de statistique de la Société juridique de Moscou, il fut par ailleurs membre de l'Institut international de statistique à partir de 1885 . V. I. Orlov avait fait sa connaissance à l'époque de ses études au séminaire de Kaluga. Il resta proche de lui jusqu'à son décès.

125. K. A. Verner (1850-1902) : agronome de formation, il dirigea le bureau statistique du zemstvo de la gubernija de Tauride de 1884 à 1889, après avoir été adjoint de V. I. Orlov dans celui du zemsvo de Moscou de 1880 à 1884 . K. A. Verner et S. A. Harizomenov effectuèrent le recensement par ménage de l'uezd de Melitopol', à l'occasion duquel ils utilisèrent, pour la première fois en Russie, des tableaux croisés mettant en relation foyers paysans et quantité des semences.

126. GASO, f. R-1, op. 1, d. 233,1.1. 


\section{Des sociétés et des congrès actifs}

Se superposant aux liens individuels entre les hommes, les sociétés de statistique jouèrent un rôle central dans la formation du corps professionnel des statisticiens des zemstva. À travers leurs débats, elles contribuèrent à construire et à diffuser un savoir scientifique et une pratique professionnelle. En particulier, elles stimulèrent l'élaboration de programmes d'enquêtes communs et de questionnaires uniformes pour les différentes provinces. Dans la tradition des sociétés scientifiques de l'époque, elles examinaient les travaux de leurs membres, leur méthodologie et leurs résultats, et élaboraient des programmes d'observation qui étaient suivis par leurs sociétaires dans les différentes régions russes ${ }^{127}$.

Si la Société russe de géographie joua un rôle essentiel dans la conception des travaux de la statistique d'État du Comité central de la statistique, de son côté, la Société juridique de Moscou, créée en 1863, servit de cadre à la définition des programmes d'enquêtes des statisticiens des zemstva et à la diffusion de nouvelles méthodes d'observation à partir de l'année 1882. À cette date, V. I. Orlov, A. I. Čuprov et M. A. Sablin ${ }^{128}$ y fondèrent une section de statistique en nourrissant l'espoir d'établir un programme uniforme d'enquêtes pour l'ensemble des gubernii russes. En 1883, cette section comptait 22 représentants de différentes provinces sur un total de 59 membres. En 1887, elle organisa la première conférence des statisticiens des zemstva. Le principe de la réalisation d'une enquête sur la situation économique des villages ruraux y fut discuté et adopté ${ }^{129}$. Le projet consistait à effectuer des recensements exhaustifs par ménage des exploitations paysannes dans l'ensemble des zemstva. La publication des résultats les plus importants fut également envisagée, ainsi que l'édition de recueils spéciaux consacrés à leur analyse. Si la nécessité de mener ces études en respectant des directives communes fit l'unanimité, dans la pratique, la diversité des conditions matérielles d'enquête d'un zemstvo à l'autre, notamment des sommes d'argent allouées par chaque administration locale, fit abandonner le projet d'un formulaire d'enquête standardisé pour tous. Toutefois, l'idée en était lancée. C'est également lors de la conférence de 1887 que fut préconisé un usage plus grand de la construction de tableaux de classification par catégories d'une population.

Outre la diffusion de la réalisation des recensements par ménage dans tous les zemstva, la Société juridique stimula l'introduction de la pratique des sondages pour mener des enquêtes approfondies selon les différents types d'exploitations. En

127. Cf. V. R. Lejkina-Svirskaja, op. cit.

128. M. A. Sablin (1842-1898) : après avoir effectué ses études à la faculté de droit de l'université de Moscou, puis à celle de Saint-Pétersbourg, il enseigna la géographie dans des établissements d'enseignement secondaire de Moscou. En 1868, il devint secrétaire du comité de statistique de la gubernija de Moscou, poste qu'il occupa jusqu'à sa mort. À partir du milieu des années 1880, il fut membre de l'assemblée municipale de Moscou. Il apporta un soutien décisif à la création du bureau statistique du zemstvo de Moscou. Il était vice-président de la section de statistique de la Société juridique de Moscou à sa création.

129. Cf. R. E. Johnson, art. cit. 
son sein également furent débattues les questions liées à l'utilisation des sondages pour construire une typologie des villages ruraux. On y examina aussi les questions posées par l'organisation d'études sur des échantillons de budgets paysans. Autre innovation majeure, le principe de la réalisation d'un recensement tous les cinq ans fut décidé au cours d'une réunion de l'année 1893. Après sa fermeture, en 1898, d'autres sociétés, en particulier la Société libre d'économie et la Société des naturalistes et des médecins russes, jouèrent un rôle important dans la diffusion d'un savoir statistique construit au contact du terrain.

La Société libre d'économie, d'existence beaucoup plus ancienne ${ }^{130}$, remplit un rôle scientifique non négligeable. En 1900, sa commission statistique convoqua une conférence de statisticiens. Le principe de la production de recensements à intervalles réguliers y fut recommandé une nouvelle fois. Parmi les résolutions prises fut affirmé le caractère indispensable de la réalisation d'enquêtes sur l'activité artisanale, sur les différenciations sociales dans les campagnes et sur la structure socioéconomique des exploitations paysannes. Cette commission fut aussi très active dans son effort d'inventaire, de collecte et de conservation des publications statistiques des différents zemstva et dans son action de diffusion du savoir statistique. Après avoir, en 1899, réalisé un inventaire des travaux de statistique courante des différents zemstva, un de ses membres, V. F. Karavaev, publia en 1911 un recueil bibliographique des travaux statistiques d'évaluation et des études économiques édités dans tous les zemstva de l'Empire russe. Plus de 8000 ouvrages y étaient recensés. Il établit également un répertoire bibliographique des ouvrages statistiques édités par les zemstva de leur création, en 1864, à $1903^{131}$.

Le rôle joué par la section de statistique de la Société des naturalistes et des médecins russes dans l'élaboration et la diffusion d'un savoir statistique commun s'exerça tout particulièrement, comme nous le verrons un peu plus loin, à la faveur de la convocation régulière de congrès.

En 1912, la Société juridique de Moscou renaquit de ses cendres à l'initiative de la section de statistique de l'université de Moscou et de N. A. Kablukov. Sous le nouveau nom de Société Čuprov, elle joua le même rôle de rassemblement national des statisticiens russes que son aînée. Néanmoins, signe déjà d'un nouvel âge de la statistique russe, ses conférences et ses débats portèrent beaucoup plus sur des questions de théorie statistique que sur l'organisation concrète d'enquêtes ${ }^{132}$. L'expérience de celles-ci était désormais acquise, sans doute aussi une forme d'homogénéisation, à défaut de standardisation.

Ces sociétés ne possédaient pas toutes des sections en province, seule celle des naturalistes était représentée à Saratov. Leur influence dans les régions s'exerçait toutefois par la voix des statisticiens du zemstvo qui en étaient membres et qui, au

130. La Société libre d'économie avait été créée en 1765. Cf. M. V. Ptuha, Očerki po istorii statistiki v SSSR (Essais sur l'histoire de la statistique en URSS), Moscou, Izd. akademii nauk, 1955, t. 1, pp. 390-394. À la fin du XIX e siècle, cette société était d'orientation libérale.

131. V.F. Karavaev, op. cit.

132. Cf. R. E. Johnson, art. cit., pp. 358-359. 
retour de chaque rassemblement national, faisaient un compte rendu des débats à leurs collègues. Les statisticiens du bureau de Saratov étaient très actifs dans la section locale de la Société des naturalistes. N. N. Černenkov était membre de son conseil local, V. I. Serebrjakov l'y remplaça après son départ de Saratov ${ }^{133}$. Les statisticiens du bureau participaient de manière tout aussi active à ses congrès nationaux. Les directeurs successifs y firent des exposés sur des questions de méthodologie et d'organisation ${ }^{134}$. Outre cela, les statisticiens de Saratov firent de certaines sociétés locales des lieux de discussion et de diffusion des résultats de leurs enquêtes. Ce fut le cas en particulier, à partir de 1901, de la Société sanitaire ${ }^{135}$, dans laquelle ils côtoyaient les médecins du zemstvo et discutaient avec eux des enquêtes sur le mouvement naturel de la population, sur la situation alimentaire de la gubernija, sur les causes sociales des maladies et de la mortalité.

Dès les années 1880, ces sociétés scientifiques locales fonctionnaient déjà comme des associations professionnelles qui se distinguaient des sociétés savantes d'érudits, telle la commission des archives, dont l'activité restait centrée sur des études locales à caractère historique, géographique et ethnographique. Spécialisées, réunissant les membres d'une même profession ou de professions qui partageaient les mêmes préoccupations, elles avaient pour objectif de discuter et appliquer localement les programmes de travail et de recherche arrêtés dans leurs instances nationales.

L'action des sociétés scientifiques était renforcée par celle des congrès professionnels. Ceux-ci étaient un moment fort de rassemblement et d'échanges entre les membres d'une profession, qu'ils réunissaient à l'échelle d'une gubernija ou d'un uezd tout autant qu'à l'échelon national. B. B. Veselovskij a dénombré 87 congrès d'agronomie et de statistique, 301 congrès de médecins et 158 congrès de vétérinaires organisés par les zemstva entre 1870 et $1905^{136}$.

Après la première conférence nationale des statisticiens des zemstva de 1887 , de nombreuses autres occasions de rencontres suivirent, en particulier à la faveur des congrès de la Société libre d'économie et de la Société des naturalistes et des médecins, qui étaient très largement fréquentés par les statisticiens. Participant aussi bien à leurs propres congrès de spécialité qu'à ceux d'autres professions, notamment des médecins et des enseignants, les statisticiens des zemstva bénéficièrent ainsi très tôt de nombreux espaces de discussion. Ces rassemblements réguliers contribuèrent à rompre leur isolement en province.

En offrant un espace de confrontation de leur pratique aux uns et aux autres, les congrès de statisticiens servaient de relais à l'action des sociétés de statistique. On y rapportait et comparait les méthodologies et les résultats des enquêtes menées dans

133. Cf. Adres-kalendar' Saratovskoj gubernii na 1906 g. (Almanach de la gubernija de Saratov de l'année 1906), Saratov, 1906.

134. Voir, par exemple, V. I. Serebrjakov, «K voprosu o postanovke tekuščej statistiki... », art. cit.

135. À partir de 1901, la Société sanitaire fit partie des sociétés les plus actives de Saratov.

136. B. B. Veselovskij, op. cit.,t. 2, p. 472. 
les différentes gubernii dans l'objectif d'en généraliser les acquis. De nouvelles méthodes d'observation, de traitement et d'analyse des données y étaient présentées et recommandées. Le bilan en était fait lors des congrès suivants. Ainsi les zemstva apparaissent comme de vastes terrains d'expérimentation d'une statistique en construction dans ses deux dimensions, théorique et pratique, les congrès remplissant la fonction de rendez-vous réguliers pour en faire le bilan, entériner, accumuler, généraliser et diffuser les acquis, pour abandonner les essais erronés et promouvoir de nouvelles méthodes ou problématiques à explorer.

Espaces privilégiés de l'élaboration d'un savoir théorique et pratique par les représentants d'un corps de professionnels en formation, les congrès contribuèrent en retour à forger les représentations, les valeurs et les repères communs à l'ensemble du groupe. Ils furent des lieux de définition des principes communs du travail statistique, ainsi que des instances de discussion sur l'organisation de son cadre institutionnel. Ils affirmèrent chaque fois la nécessité d'unifier la conception des enquêtes des différents bureaux à des fins de comparabilité.

En outre, comme on l'a déjà évoqué plus haut à la suite de N. M. Pirumova ${ }^{137}$, l'analyse de la signification sociale de ces rassemblements doit prendre en compte le rôle qu'ils ont joué dans la dynamique du mouvement libéral des zemstva. Ces congrès professionnels furent aussi des espaces de débat politique, ce qui souligne par ailleurs leur dimension éthique. Ils contribuèrent fortement à l'organisation progressive d'un mouvement d'opposition des zemstva au pouvoir tsariste, dont les membres pouvaient se reconnaître dans le partage de valeurs autres que purement professionnelles. Non seulement les statisticiens ne furent pas en reste dans ce processus d'ensemble, mais ils figurèrent souvent parmi les plus actifs ${ }^{138}$. En cela, l'étude de la dynamique de la structuration de ce corps de professionnels à travers ses sociétés et ses congrès est inséparable de celle du mouvement libéral des zemstva. On voit que ce mouvement de professionnalisation a une signification sociale plus large que celle d'un simple processus d'organisation d'une profession. L'analyse de la formation d'un ethos professionnel commun à l'ensemble des statisticiens des zemstva ne peut pas faire abstraction de sa dimension sociale et politique.

\section{Des monographies locales à portée générale}

Ainsi la pratique professionnelle de ces hommes était-elle l'expression d'un système de références intellectuelles qui dépassait largement le cadre local, ce qui fait sortir cette statistique régionale de sa singularité. À la lecture des comptes rendus de synthèse de différentes enquêtes, on garde effectivement l'image d'une production statistique locale non isolée du reste du pays, et même du reste de l'Europe. S. A. Harizomenov, par exemple, s'efforçait de définir sa méthodologie

137. N. M. Pirumova, op. cit.

138. Ibid. 
des recensements par ménage par comparaison avec celle des recensements européens. Cela l'amenait, en particulier, à retenir le terme français de « ménage » pour expliciter l'expression russe podvornye perepisi :

«Pour définir les unités d'une enquête, il était d'usage non pas de prendre une personne en particulier, mais un ménage-exploitation auquel se rapportaient toutes les données sur la population et la situation économique. Sous le terme d'exploitation on entend une union de personnes ayant une source commune et indivise de moyens de subsistance. Une telle définition ne correspond ni au ' $d v o r$ ', qui est fondé sur une habitation commune, ni à la famille, dont la composition est déterminée par les liens de sang ; elle se rapproche bien plus, bien que de manière incomplète, du 'ménage'139 des recensements européens. »' 140

Par un tel souci, S. A. Harizomenov indique très clairement la proximité entre ses préoccupations et celles des statisticiens européens. On est loin d'une conception de l'enquête statistique centrée sur les seuls besoins d'un zemstvo. Il s'agit bien plus d'un effort de construction des outils d'une analyse scientifique visant à la reproductibilité de leur utilisation dans quelque type de société que ce soit et à la comparabilité des résultats. Dans le même esprit, les résultats des enquêtes d'un zemstvo étaient souvent interprétés à la lumière des données concernant d'autres gubernii, voire d'autres pays européens. C'était le cas notamment des études sur les migrations de population et sur les causes sociales des maladies et de la mortalité.

Replacée dans une démarche comparative, la monographie régionale prend ainsi tout son sens. L'interprétation des données s'en trouve plus fine, plus approfondie, dépassant le simple constat pour atteindre à l'interrogation de fond sur les mécanismes d'un phénomène, pour atteindre au général. N. N. Černenkov a développé ses travaux fondateurs sur la relation entre le cycle de vie familial et les transformations des exploitations paysannes en procédant ainsi, à partir d'une série d'enquêtes effectuées dans le zemstvo de Saratov ${ }^{141}$. Au milieu des années 1920, A. I. Hrjaščeva, directrice adjointe de la Direction centrale de la statistique soviétique, y faisait encore référence dans ses travaux ${ }^{142}$.

La Saratovskaja zemskaja nedelja, revue du conseil du zemstvo de Saratov, se fit largement l'écho des travaux à portée générale des statisticiens du bureau de Saratov. À côté de leurs propres recueils de statistique, plutôt destinés à un usage local, ces hommes trouvèrent, grâce à cette revue, une audience nationale. Les articles qui y étaient publiés étaient d'un tout autre genre que ceux des recueils. Par leurs thèmes et par leurs questions ils s'inscrivaient dans les débats qui animaient les sociétés et les congrès de statistique. C'est ainsi que l'étude de N. N. Černenkov

139. Ce terme est écrit en français dans le texte russe original.

140. S. A. Harizomenov, Svod..., op. cit., p. 20.

141. N. N. Černenkov, art. cit.

142. A. I. Hrjaščeva, « Metody nabljudenija dinamiki zemledel’českogo hozjajstva » (Les méthodes d'observation de la dynamique de 1'exploitation agricole), Vestnik statistiki, 1-3, 1924,pp. 83-119. 
sur les transformations des exploitations agricoles familiales put paraître la première fois. Quelques articles fondamentaux de statistique agricole de V. M. Obuhov furent publiés de cette manière également ${ }^{143}$. Presque tous les statisticiens du bureau de Saratov fournirent des articles de fond à la Nedelja. Publication de réseau, c'est le rôle que semble avoir joué cette revue qui, d'après Robert Philippot, faisait partie des deux périodiques de zemstvo les plus connus en Russie à cette époque et qui, « plutôt destinée aux lecteurs cultivés », contenait des articles d'intérêt plus général que local144. Une de ses six sections, le zemskij otdel, était consacrée à l'actualité de l'activité des zemstva. Émanation de l'élite intellectuelle du zemstvo de Saratov, la Nedelja ouvrait ses pages également aux hommes d'autres zemstva, connus, comme B. B. Veselovskij ${ }^{145}$, ou moins connus. À ce titre, elle était, comme le souligne N. M. Pirumova ${ }^{146}$, un des organes d'expression du mouvement libéral des zemstva. À partir de la fin des années 1890, à en croire A. A. Argunov, elle devint la voix tout à la fois des représentants libéraux du zemstvo et de nombreux membres du groupe socialiste révolutionnaire de Saratov ${ }^{147}$. La durée de sa parution, de 1893 à 1905, témoigne d'une réelle volonté de publication de la part du conseil du zemstvo de Saratov. Arrêtée après la révolution de 1905, sa parution reprit en 1917 et 1918.

Si les statisticiens de Saratov y disposaient d'un espace privilégié pour leurs propres écrits, ils y soutinrent aussi la publication d'articles de confrères d'autres provinces. Ainsi V. G. Groman put-il publier différents comptes rendus au sujet de la méthode de construction des échantillons par aires types qu'il avait utilisée dans les enquêtes effectuées pendant son exil dans la province de Vjatka entre 1898 et 1900 et, ensuite, au cours de son exil en Sibérie orientale entre 1902 et $1905^{148}$. On pouvait y trouver également des articles de statistique sanitaire du zemstvo de Voronež ${ }^{149}$, ainsi que des études de statistique de l'assurance de différents

143. Citons notamment V. M. Obuhov, « Uslovija denežnoj arendy zemel' v 1900 godu » (Les conditions du loyer des terres en 1900), Saratovskaja zemskaja nedelja, 38-41, 1901, pp. 1-10 ; « Povyšaetsja ili ponižaetsja urožajnost' v Rossii? » (Le rendement augmente-t-il ou diminuet-il en Russie?), Saratovskaja zemskaja nedelja, 2, 1903, pp. 7-12 ; «Opyt učeta urožaja v Balašovskom uezde v 1903 godu po hozjajstvennym gruppam krest'janstva » (Essai de comptabilité des récoltes dans l'uezd de Balašov en 1903 par catégories d'exploitations paysannes), Saratovskaja zemskaja nedelja, 1, 1904,pp. 43-50.

144. R. Philippot, op. cit., p. 93. Le second périodique était la Vjatskaja gazeta, destinée à un lectorat plus populaire.

145. Citons, par exemple, B. B. Veselovskij, «Zemskie vybory v Balašovskom uezde » (Les élections au zemstvo dans l'uezd de Balašov), Saratovskaja zemskaja nedelja, 8, 1903.

146. N. M. Pirumova, op. cit.

147. A. A. Argunov, « Iz prošlogo partii socialistov revoljucionerov » (Sur le passé du parti des socialistes révolutionnaires), Byloe, 10, 1907, pp. 103-105.

148. À ce sujet, voir « $\mathrm{K}$ tridcatiletiju statističeskoj i naučnoj raboty V. G. Gromana » (Pour les trente ans de travail statistique et scientifique de V. G. Groman), Vestnik statistiki, 2, 1927, pp. I-VIII.

149. Voir, par exemple, Aljančikov, « Derevnja Otrožki Voronežskogo uezda v sanitarnom otnošenii » (La situation sanitaire du village de Otrožki dans l'uezd de Voronež), Saratovskaja zemskaja nedelja, 11-12, 1904, Appendice, pp. 1-77. 
zemstva $^{150}$. La Saratovskaja zemskaja nedelja était devenue un organe de diffusion des résultats des enquêtes et des articles théoriques des statisticiens de la sphère des zemstva. Elle était aussi une affaire de famille. Z. A. Serebrjakova, femme de V.I.Serebrjakov, y fut journaliste de 1896 à 1899151. Un autre statisticien, V. S. Golubev, en fut longtemps rédacteur en chef.

\section{Un engagement social local, un projet politique national}

\section{Observateurs et acteurs du social}

Les statisticiens du zemstvo de Saratov font songer à la figure du savant du $\mathrm{XIX}^{\mathrm{e}}$ siècle, épris de connaissance et de progrès. Observateurs du social, ils étaient également soucieux d'agir et aspiraient au changement social. Acteurs du social, ils le furent chacun à sa manière, soit en assumant des fonctions électives, soit en participant activement à des sociétés d'assistance, soit en développant une forme de militance sociale au sein de cercles culturels dans lesquels ils pouvaient exposer et diffuser non seulement les résultats de leurs enquêtes statistiques, mais également leur propre vision de la société et du changement. Leur action sociale s'articulait avec leur activité professionnelle. Tous les statisticiens du bureau du zemstvo, en particulier ses responsables, directeurs et directeurs adjoints, participèrent activement à la vie des sociétés locales.

S. A. Harizomenov était, on l'a vu, membre actif de la section de Saratov de la Société d'agriculture. À ce titre, en 1889, il prit part à l'organisation de l'exposition du zemstvo sur l'agriculture et l'industrie artisanale152. En 1893, il fut à l'initiative du premier congrès des exploitants agricoles des sept gubernii du sud-est de la Russie. Comme on l'a déjà mentionné, il fut également membre actif, dès sa création, de la Commission scientifique des archives de Saratov. Le discours qu'il prononça en décembre 1889, à l'occasion de l'anniversaire des trois premières années d'activité de cette société, livre des indications sur la manière dont certains statisticiens comme lui concevaient leur insertion dans la vie intellectuelle et scientifique locale ${ }^{153}$. Il y développe longuement sa conception de l'apport scientifique d'une société savante de province telle que celle-ci :

150. Par exemple, I. Borisov, «O rabotah po strahovoj statistike v gubernskih zemstvah $\mathrm{k}$ 1902-mu godu » (Les travaux de statistique des assurances dans les zemstva des gubernii en 1902), Saratovskaja zemskaja nedelja, 1, 1904, pp. 58-67 ; P. Azarevič, «O praktičeskih zadačah strahovoj statistiki » (Les tâches pratiques de la statistique des assurances), Saratovskaja zemskaja nedelja, 6-7, 1904, pp. 124-133.

151. GASO, f. 5, op. 2, d. 1244, 11. 1,3.

152. V.P. Kornev, op. cit., p. 165.

153. Entre 1899 et 1905, V. M. Obuhov a été, lui aussi, membre de la Commission scientifique des archives de Saratov. Cf. V.P. Sokolov, ed., «25-letie Saratovskoj učenoj arhivnoj komissii, 1886-1911 g. Istoričeskij očerk » (Anniversaire des 25 ans de la Commission scientifique des archives de Saratov, 1886-1911. Essai d'histoire), Trudy Saratovskoj učenoj arhivnoj komissii, 28, 1911, p. 26. 
«La commission des archives, en tant qu'organisation régionale dont les membres n'appartiennent pas au milieu des spécialistes historiens et des archéologues officiels, devient une arme puissante pour la popularisation de la science, pour son harmonisation avec la vie et la société. Très proches de leur région, de sa géographie et de la situation présente de la population, les membres de la commission des archives éviteront plus facilement, dans leurs travaux, les erreurs dans lesquelles tombe de manière involontaire le savant qui travaille dans son cabinet, qui n'a pas d'autres moyens à sa portée pour vérifier ses conclusions que ceux fournis par les matériaux écrits ou imprimés. »154

Pour le statisticien, la proximité entre les membres de la commission et la population locale permet d'assigner une double mission à cette société savante. Tout d'abord, elle est investie d'un projet de diffusion du savoir scientifique auprès d'un public large. Par ailleurs, cette proximité offre l'opportunité à ses membres de recueillir les informations nécessaires pour vérifier les conclusions scientifiques énoncées dans les espaces savants d'élaboration du savoir que sont les universités. En cela résiderait l'originalité de l'apport de ces sociétés de «chercheurs locaux» (mestnye issledovateli): confronter les résultats des travaux universitaires avec les données du terrain et des documents administratifs locaux. Suit un développement sur l'apport de l'étude des documents d'archives locaux pour une meilleure compréhension non seulement des questions locales, mais également des questions à portée plus générale :

« Pour les chercheurs locaux, l'étude détaillée de documents sur place revêt une grande importance, ce dont les savants des universités de la capitale sont privés. L'analyse des archives rend plus clairs les problèmes juridiques et les litiges liés à la terre qui sont instruits par nos tribunaux et nos services administratifs. Les actes de donation, les documents conservés dans les églises et les récits faits par les vieux habitants nous indiquent l'année du peuplement, le moment où ont commencé l'exploitation de la terre et la pollution du sol. Le premier fait est important pour notre agronomie, le second pour la médecine sanitaire. ${ }^{155}$

On retrouve bien là la démarche des recensements par ménage : tout inventorier, ne laisser de côté aucun détail, aucun document, aucune information susceptible d'aider à la meilleure compréhension du phénomène observé. Ainsi trouve sa place, à côté de la « science universitaire » (universitetskaja nauka), une autre forme de production du savoir que S. A. Harizomenov n'hésite pas à baptiser «science régionale » (oblastnaja nauka), et dont l'existence est justifiée par sa complémentarité avec la première :

«Cela ne fait pas de doute, toutes ces questions ne peuvent pas intéresser autant les représentants de la science universitaire; dans leurs exposés nous ne

154. S. A. Harizomenov, «Značenie russkih arhivnyh kommissij dlja russkoj istoričeskoj nauki i russkogo obščestva » (L'importance des commissions des archives russes pour la science historique russe et la société russe), Trudy Saratovskoj učenoj arhivnoj komissii, 1, vol. 3, 1890 (Traduction de N. Youmatoff).

155. Ibid. 
trouverons sûrement pas les indications détaillées qui pourraient nous aider à résoudre les besoins et les questions liés à la région. Voilà la raison pour laquelle la science régionale, élaborée par les chercheurs locaux, évidemment sous la direction de spécialistes scientifiques, possède le même droit à l'existence que la science de l'ensemble de l'Empire. »

C'est donc également son objectif pratique, au service des besoins de l'économie et de la société locales, qui justifie l'existence d'une « science régionale » aux côtés de la science académique. Toutefois, précise S. A. Harizomenov, même si elle doit être à la portée de tous, elle ne doit pas souffrir d'amateurisme. Guidés par des spécialistes locaux du domaine étudié, les chercheurs amateurs de la commission des archives devront «discipliner rigoureusement leur esprit», faire œuvre de démarche scientifique. Les sociétés savantes locales sont alors présentées comme une « école pour apprendre les procédés scientifiques de la pensée ». Le rôle d'un savant en province semble conçu au cœur de ce projet pédagogique, à l'intersection de son activité professionnelle et d'une forme d'engagement dans la vie publique locale.

Plaidoyer en faveur de ce qu'il présente comme une «démocratisation de la science », ce discours d'anniversaire de S. A. Harizomenov apparaît comme une forme de synthèse entre son projet scientifique et son projet social. Synthèse entre une pensée sociale marquée par l'esprit des Lumières et une forme d'héritage de son passé populiste, la science, pour ce statisticien, doit donc être « au service du peuple ». Dans son cas, activité sociale et activité professionnelle semblent avoir constitué un tout, deux facettes différentes et complémentaires d'un même engagement social. On ne peut s'empêcher de penser à ces hommes du XIX ${ }^{\mathrm{e}}$ siècle qui, à la manière de Le Play, ont mis leur savoir scientifique au service d'une forme d'intervention sociale ${ }^{156}$.

La participation des statisticiens à la vie publique de leur province pouvait prendre d'autres formes. Comme beaucoup de leurs collègues, les deux directeurs suivants du bureau, N. N. Černenkov et V. I. Serebrjakov, étaient membres de la section locale de la Société des naturalistes et des médecins. Pour sa part, N. I. Rakitnikov fut un sociétaire actif de la Société des amateurs des Beaux-Arts pendant les années 1890. Là, à l'exemple d'autres populistes comme M. A. Natanson ${ }^{157}$, il trouva une arène pour exposer ses idées, à la faveur des spectacles présentés, mais aussi des soirées culturelles, notamment celles destinées à la

156. À ce sujet, on pourra se reporter à Frédéric Le Play, Les Mélouga : une famille pyrénéenne au $X I X^{e}$ siècle, Présentation et postface de Alain Chenu, Paris, Nathan, 1994. Voir également Bernard Kalaora, Antoine Savoye, Les inventeurs oubliés. Le Play et ses continuateurs aux origines des sciences sociales, Paris, Champ Vallon, 1989.

157. M. A. Natanson (1850-1919) fut un des fondateurs de l'organisation Zemlja i volja. Il arriva à Saratov au retour de son premier exil en Sibérie, en 1889. Au début des années 1890, il y dirigeait le groupe local des populistes, dont beaucoup de membres arrivaient également d'exil politique. Ce groupe fut particulièrement actif dans les milieux intellectuels locaux et auprès des élèves des gymnases. Il avait des liens avec celui de Nižnij Novgorod, auquel appartenaient, à cette époque, N. F. Annenskij et V. G. Korolenko. En 1905, M. A. Natanson devint un des responsables nationaux du parti socialiste révolutionnaire. 
jeunesse ${ }^{158}$. Des exposés sur des textes littéraires servaient de support aux discussions politiques. Populistes et libéraux avaient l'habitude de se côtoyer au sein des sociétés culturelles locales, en particulier dans celle-ci ${ }^{159}$.

Dans le cas des sociétés d'assistance, les responsabilités sociales assumées individuellement par les statisticiens pouvaient sembler incluses dans la large sphère d'intervention du zemstvo, qui leur servait de support matériel ou institutionnel. Ainsi en était-il de la présidence de la Société d'assistance aux hommes de lettres dans le besoin, assurée un temps par V. I. Serebrjakov ${ }^{160}$. Celui-ci était également membre du conseil d'administration de la Caisse de crédit et d'épargne des employés du zemstvo. De son côté, A. F. Milovzorov était bibliothécaire de la Société d'assistance aux travailleurs du commerce et de l'industrie ${ }^{161}$.

Dans un autre domaine, la commission d'organisation de la lecture publique avait son siège dans les locaux administratifs du conseil du zemstvo. Section à part entière de la Société des médecins sanitaires, elle semble avoir offert un espace d'engagement social privilégié à beaucoup de statisticiens de Saratov. En 1898, V. I. Serebrjakov en était trésorier ${ }^{162}$. L'action de cette commission fut complétée, après 1900, par celle de la Société des universités populaires, qui ouvrit un établissement de ce type à Saratov en décembre 1906163. Au début de l'année 1908, il n’y avait que neuf universités populaires dans toute la Russie. Les statisticiens furent particulièrement actifs au sein de celle de Saratov qui, dès sa création, invita N. A. Kablukov pour une série de conférences sur l'économie politique ${ }^{164}$.

En même temps qu'une géographie de leur engagement social, c'est donc une carte de l'insertion de ces statisticiens dans l'espace des élites locales qui se dessine peu à peu.

\section{Des acteurs de la vie politique locale}

Les assemblées d'uezd et de la gubernija pouvaient offrir aux professionnels du «troisième élément» l'opportunité de faire entendre une voix différente, soit quand ils étaient invités à titre d'experts pour éclairer les discussions, soit quand, issus eux-mêmes de la noblesse foncière locale, ils prenaient part aux débats et au

158. Cf. V. V. Širokova, Partija narodnogo prava (Le parti du droit du peuple), Saratov, 1972, pp. 32-50.

159. À ce propos, voir D. J. Raleigh, op. cit., pp. 46-51.

160. Cf. Adres-kalendar' Saratovskoj gubernii na 1900 g. (Almanach de la gubernija de Saratov de l'année 1900), Saratov, 1900.

161. Ibid., année 1898.

162. Ibid.

163. Saratovskij vestnik, 28/02/1907. La première université populaire de Russie, l'université Šanjavskij, avait ouvert à Moscou en septembre 1906, suivie par celle de Saint-Pétersbourg en octobre. Cf. V. R. Lejkina-Svirskaja, op. cit., p. 77.

164. Cf. N. A. Kablukov, « Avtobiografija », art. cit., p. 13. 
vote. Parmi les statisticiens, tel fut le cas de V. M. Obuhov. Sa qualité de noble lui valut de siéger, de 1903 à 1906, à la fois dans l'assemblée du zemstvo de l'uezd de Balašov et dans celle de la gubernija ${ }^{165}$. À ce titre, il était également membre de certaines commissions de l'assemblée de la gubernija. Ainsi prit-il une part active à la commission d'évaluation. Il siégeait par ailleurs au sein du conseil économique de la gubernija de Saratov ${ }^{166}$. Un témoignage de la forme de la participation de ce statisticien au débat politique local nous a été laissé dans un compte rendu, publié dans la revue Osvoboždenie ${ }^{167}$, de la séance du 9 janvier 1905 de la commission de l'assemblée du zemstvo de Saratov. Celle-ci avait été convoquée pour discuter et soumettre au vote les onze points du programme de réforme de la vie politique, en particulier du système législatif et des droits individuels, qui avait été élaboré par le congrès national des zemstva du 6 novembre $1904{ }^{168}$. Ce texte illustre la manière dont un professionnel du zemstvo d'origine noble pouvait profiter de sa position sociale pour porter au niveau local l'écho de débats à enjeu national.

À l'occasion des échanges qui portèrent sur le sixième point du programme, relatif à la notion de « liberté politique », le statisticien plaida pour y inclure le droit de grève :

«Ici il est dit: liberté de réunion et d'association. J'estime indispensable d'ajouter à cela : et de grève. Bien que la liberté de faire grève ne relève pas des droits politiques, c'est une action collective qui, à cause de ce caractère, occupe une place particulière. Si je refuse de travailler, mon refus individuel n'est pas un délit ; mais si ce refus est collectif, déjà il devient passible de condamnation. J'estime qu'il est indispensable d'inclure la liberté de faire grève dans ce sixième point. »169

L'argumentation employée montre le décalage qu'il pouvait y avoir entre les préoccupations d'hommes appartenant à une élite intellectuelle urbaine et celles de nobles modérés ou conservateurs aux préoccupations avant tout locales, soucieux de préserver un ordre des campagnes pourtant déjà bien menacé. Devant les protestations de divers membres de l'assemblée, c'est justement sur le caractère inéluctable du changement que V. M. Obuhov insista :

«Les événements des jours derniers servent, je pense, d'argument suffisant pour cela. Nous savons que l'absence de liberté de faire grève conduit souvent aux effusions de sang. »

165. Cf. Adres-kalendar' Saratovskoj gubernii na 1906 g., op. cit.

166. Ibid., années 1898 et 1906.

167. Zemstvo i političeskaja svoboda (Le zemstvo et la liberté politique), Osvoboždenie, numéro spécial, Paris, mars 1905.

168. À ce sujet, voir V. Léontovitch, op. cit.,pp. 284-293. La majorité du congrès vota pour un passage au régime constitutionnel dans le respect du pouvoir tsariste, avec une constitution octroyée par le tsar. Des libéraux de gauche, comme N. N. L'vov, défendirent l'idée que les réformes devaient être réalisées en accord avec le tsar.

169. Zemstvo i političeskaja svoboda, op. cit., p. 12. 
La position prise par le statisticien à propos de la législation électorale proposée par le congrès national des zemstva montre à la fois la proximité et les différences qu'il y avait à ce sujet, au début de l'année 1905, entre un marxiste comme lui et les libéraux. Pendant la discussion sur les modalités des élections aux diverses assemblées du zemstvo et de la municipalité, il adopta une attitude plus ferme que celle du texte à propos du principe de l'élargissement de la représentation dans ces instances à l'ensemble des couches de la population :

« Dans ce point, il est dit qu'il faudrait attirer 'dans la mesure du possible' toutes les forces de la population pour participer à l'auto-administration des zemstva et des villes. Eh bien, ces mots 'dans la mesure du possible' sont en contradiction avec le point 7, dans lequel il est dit que les droits politiques et civils doivent être égaux pour tous. Je propose de supprimer cette phrase 'autant que possible'. [Devant les réticences de certains, il ajouta] : «Non, il le faut. Les forces, ce sont les couches de la population. 'Autant que possible', cela signifie déjà 'pas tous'. »170

Dans un de ses rapports de gouverneur, Stolypin notait que le groupe des libéraux, bien que «d'importance sensiblement égale à celui des nobles conservateurs », était le plus influent parce qu'il possédait « tous les bons orateurs » et que les autres membres de l'assemblée, « réticents mais passifs, suivaient le mouvement par intimidation ou par peur de paraître rétrogrades ${ }^{171}$. Comme le montrent les extraits ci-dessous, la manière dont une majorité se dégagea quand V. M. Obuhov proposa le vote à bulletin secret pour les élections à l'assemblée du zemstvo confirme la remarque de Stolypin. Elle suggère également que, dans ce genre de situation, les libéraux pouvaient bénéficier du soutien de professionnels du zemstvo d'appartenance ou de sensibilité politique plus radicale. «L'alliance libérale-radicale » trouvait là un autre mode d'expression. Le statisticien dit d'abord : « Messieurs, là il est dit : 'suffrage universel', mais il n'est pas mentionné que c'est 'à bulletin secret'. Je demande d'introduire cet additif. » ${ }^{172}$ Aux voix qui répondirent «C'est un détail !», V. M. Obuhov objecta avec fermeté : «J'avertis que sans cela, par conviction personnelle, je ne peux signer la résolution. » Sa proposition fut largement acceptée. Seules deux voix s'y opposèrent. Fidèle à sa tactique, il profita de ce succès pour engager un peu plus l'assemblée et remettre en cause le principe du vote censitaire :

« Cet additif sur le vote à bulletin 'secret' n'est pas une broutille, mais un droit fondamental du peuple ; il faut également ajouter le mot à suffrage 'égal', car vous pouvez vous approprier 20 voix et ne donner qu'une voix au simple peuple. [...] Puisse-t-on voter ici ces additifs! Alors on verra clairement si vous êtes pour les droits du peuple ou non. [...] Je répète que, si ces amendements ne sont

170. Ibid., p. 17.

171. Cf. R. Philippot, art. cit.

172. Zemstvo i političeskaja svoboda, op. cit.p. 31. 
pas introduits, je ne signerai pas. Êtes-vous pour le peuple ou contre le peuple? $»^{173}$

Autre forme de participation à la vie politique locale, à partir de 1906, des statisticiens se présentèrent à différentes élections. V. I. Serebrjakov, directeur du bureau du zemstvo, était grand électeur aux élections de la première Douma d'État en 1906, de même que d'autres hommes du bureau, I. I. Gil'genberg et P. A. Argunov ${ }^{174}$. En 1907, un de leurs collègues du zemstvo, M. E. Berezin, directeur des études statistiques du département de l'assurance, fut élu député trudovik à la deuxième Douma d'État ${ }^{175}$. Quant à N. N. Sirotinin, il fut élu à la Douma municipale en mai 1905. L'année suivante, il était grand électeur aux élections à la première Douma d'État. En 1915, il siégeait encore à la Douma municipale ${ }^{176}$.

\section{Des statisticiens dans la révolution}

À Saratov, les événements de l'année 1905 se sont déroulés dans un contexte particulier. Stolypin y était gouverneur depuis deux ans. En terre libérale et populiste, le débat sur la question agraire était d'autant plus vif que la gubernija avait connu de nombreuses émeutes paysannes depuis l'année 1901177. Les statisticiens occupaient une place particulière dans ce débat. Chargés des études d'estimation de la propriété des terres, ils étaient en train de terminer ces travaux pour l'ensemble de la province et mettaient l'accent sur la différenciation interne de la paysannerie ${ }^{178}$.

173. Ibid., p. 32.

174. Voir les documents photographiques du fonds du Musée d'histoire locale de Saratov consacré à la révolution de 1917.

175. Istorija Saratovskogo kraja, op. cit.pp. 299-300.

176. Entre-temps, il avait quitté l'administration du zemstvo pour devenir secrétaire général de celle de la municipalité de Saratov en octobre 1909. Cf. GASO, fonds « Saratovskaja gorodskaja uprava »(Administration de la ville de Saratov), f. 4, op. 2, d. 860,1. 10ob ; GASO, fonds «Saratovskaja gorodskaja duma » (Douma de la ville de Saratov), f. 3, op. 1, d. 4312,1. 143.

177. Entre1901 et 1904, la gendarmerie de Saratov avait enregistré 273 émeutes de différentes formes dans les campagnes de cette gubernija. Cf. I. I. Babikov, « Krest'janskoe dviženie v Saratovskoj gubernii nakanune pervoj russkoj revoljucii » (Le mouvement paysan dans la gubernija de Saratov à la veille de la première révolution russe), Učenye zapiski Saratovskogo universiteta, 55, 1956.

178. Citons, en particulier, V. I. Serebrjakov, «Zemlevladenie v Saratovskoj gubernii i stepen’ obespečennosti krest'jan zemlej » (La propriété foncière dans la gubernija de Saratov et le niveau de satisfaction des besoins en terre des paysans), in Materialy $k$ voprosu o nuždah sel'sko-hozjajstvennoj promyšlennosti v Saratovskoj gubernii (Matériaux sur la question des besoins de l'industrie agricole dans la gubernija de Saratov), Saratov, izd. Saratovskogo gubernskogo zemstva, 1903, pp. 1-65 ; V. I. Serebrjakov, ed., Materialy dlja ocenki zemel' Saratovskoj gubernii. Zemslevladenie (Matériaux pour l'estimation des terres de la gubernija de Saratov. La propriété des terres), Saratov, izd. Saratovskogo gubernskogo zemstva, 1906, 2 vols. 
Pour certains, l'année 1905 sonna le glas de leur militantisme politique. Ce fut le cas de V. M. Obuhov. À la fin du mois d'avril, il figurait parmi les délégués au congrès des bolcheviks qui se tint à Londres. En décembre, il fut arrêté et envoyé en exil dans la gubernija de Tobol'sk ${ }^{179}$. De là, il partit clandestinement à l'étranger. Quand il revint en Russie, en 1909, il cessa toute activité politique dans un parti et se consacra entièrement à son travail de statisticien.

Pour sa part, N. I. Rakitnikov quitta Saratov en 1906, deux ans après son retour. En 1903, à peine revenu de l'étranger, il avait été arrêté à Odessa, puis, l'année suivante, envoyé une nouvelle fois en exil à Saratov. Là, il avait retrouvé un poste dans le bureau de statistique. Il mena une activité politique importante dans l'ensemble de la région de la Volga, où il organisa notamment un congrès régional des socialistes révolutionnaires à la fin de l'année 1904. Parallèlement, il continuait à assumer des responsabilités au niveau national ${ }^{180}$. Il était membre du comité exécutif du parti socialiste révolutionnaire et du collectif de rédaction du journal Zemlja $i$ volja. Il participa au congrès de l'Union paysanne russe qui se tint à Moscou en novembre 1905. À cette époque, il faisait partie des éléments les plus radicaux du parti socialiste révolutionnaire. En 1906, il émigra et ne revint en Russie qu'en 1915.

Après 1905, à l'exception de V. M. Obuhov et de N. I. Rakitnikov, tous les autres statisticiens du bureau restèrent sur place, se partageant entre leur travail et leur participation au nouvel espace de la vie politique ouvert par la loi électorale de 1906. Ils y étaient encore en 1917.

Certains d'entre eux se présentèrent aux élections de juillet 1917 à la Douma de la ville de Saratov. À cette occasion, les cadets et une partie des socialistes révolutionnaires firent liste commune. Les noms de statisticiens SR du bureau, I. I. Gil'genberg, P. A. Argunov, côtoyaient ceux de candidats cadets ${ }^{181}$. De leur côté, des statisticiens extérieurs au bureau, mais proches de ses membres, figuraient sur la liste du parti des trudoviki, nombreux dans cette région de la Volga. On y trouvait notamment les noms de A. A. Rybnikov et I. N. Kokšajskij.

À la lumière de ces différents faits, une caractéristique du mode de participation des statisticiens de Saratov à la révolution de 1905 et aux événements de l'année 1917 se dégage. Au-delà des divergences ou des oppositions entre partis, ils adoptèrent les formes d'expression du jeu politique local et des alliances en œuvre jusque-là. Toutefois, les divergences d'analyse politique qui pouvaient exister entre les uns et les autres ne furent pas gommées pour autant, en particulier au sujet de la question agraire.

Dans ce tableau d'ensemble, le personnage de N. I. Rakitnikov occupe toutefois une place à part. Son engagement national semble avoir toujours commandé son militantisme local. Ainsi, en 1915, dès son retour en Russie, il fut arrêté et, une fois

179. V. P. Kornev, op. cit., pp. 105-106.

180. V. V. Šelohaev, Partija socialistov-revoljucionerov. Dokumenty i materialy, 1900-1907 gg. (Le parti des socialistes révolutionnaires. Documents et matériaux, 1900-1907), Moscou, 1996, pp. 642-643.

181. Fonds du Musée d'histoire locale de Saratov sur l'année 1917. 
de plus, envoyé en exil à Saratov. Il partagea l'année 1917 entre Saratov et Petrograd. Responsable local du parti socialiste révolutionnaire, il fut très actif à Saratov les premiers mois de l'année ${ }^{182}$. Ensuite il partit à Petrograd, où il assuma la fonction de vice-ministre de l'Agriculture auprès de V. M. Černov, ministre de l'Agriculture du Gouvernement Provisoire de mai à août 1917. Venu à la statistique régionale à la recherche d'un moyen de subsistance, il s'en éloigna une nouvelle fois quand l'occasion de jouer un rôle politique national lui fut offerte. Dans le cadre de sa nouvelle fonction, il présida le Comité agraire principal ${ }^{183}$. C'est toutefois à Saratov qu'il se présenta aux élections de novembre 1917 à l'Assemblée constituante de Petrograd. Il figurait en deuxième position, derrière A. F. Kerenskij, sur la liste locale des candidats du parti socialiste révolutionnaire ${ }^{184}$.

En fin de compte, pour N. I. Rakitnikov, Saratov semble avoir toujours joué le rôle d'une base de repli avant de pouvoir repartir à Saint-Pétersbourg ou à Moscou. Cela n'en diminua pas pour autant l'énergie qu'il consacra à son activité professionnelle et à son action politique dans cette province chaque fois qu'il y résida.

\section{Des notables de la société civile locale}

Au moment du changement du pouvoir d'État en Octobre 1917, beaucoup de statisticiens du bureau de Saratov, en particulier ceux qui occupaient une position de responsabilité, étaient devenus en quelque sorte des notables de la vie publique locale. Reconnus dans leur domaine professionnel, ils étaient des interlocuteurs écoutés du conseil et de l'assemblée du zemstvo.

À cet égard, à partir des élections à la première Douma d'État en 1906, leur participation à la vie politique au sein de partis n'avait plus la même signification que dans les années 1880 et 1890 . Elle n'était plus illégale et prenait la forme de la participation normale de citoyens au jeu d'une vie politique reposant sur un système électoral, même si celui-ci demeurait restrictif. Analystes de l'économie et de la société par leur activité professionnelle, ils étaient également, à des degrés divers, des acteurs de la gestion de ces deux sphères et de la vie publique locale. Cela ne leur était pas spécifique, mais caractérisait plus largement l'ensemble des cadres du zemstvo, particulièrement ceux qui étaient les plus impliqués professionnellement dans l'observation de la vie sociale et dans le travail au contact de la population, médecins et enseignants par exemple ${ }^{185}$.

182. À ce sujet, voir D. J. Raleigh, op. cit.

183. Au sujet du Comité agraire principal, voir A. Stanziani, op. cit., pp. 196-198.

184. Fonds du Musée d'histoire locale de Saratov sur l'année 1917. Un autre statisticien, B. N. Černenkov, président du comité agraire principal de la gubernija et vice-président du parti SR de la gubernija, était en quatrième position sur cette liste. Il s'agissait, semble-t-il, du frère de N. N. Ćernenkov, cadet pour sa part. Toutefois, cette information n'a pas pu être vérifiée de manière complètement sûre.

185. Sur les médecins, voir N.M. Frieden, «The politics of zemstvo medicine», in T. Emmons, W. S. Vucinich, op. cit. pp. 314-342. 
Leur participation à l'administration du zemstvo avait contribué à rapprocher représentants libéraux de la noblesse et employés modérés et radicaux du zemstvo autour des préoccupations de la gestion quotidienne des affaires économiques et sociales de la province. L'expérience professionnelle accumulée ainsi avait aguerri les statisticiens à la gestion des affaires publiques, à laquelle les administrateurs du zemstvo de Saratov les avaient associés au-delà de leurs seules compétences en statistique. En outre, à partir de 1906, l'expérience politique des statisticiens peut être interprétée comme un facteur qui a, en complément de leur fonction dans l'administration du zemstvo, ou dans celle de la ville de Saratov, forgé ou élargi leurs compétences d'administrateur en leur fournissant une autre expérience pratique de la gestion des affaires publiques, que certains ont utilisée ensuite dans le cadre de l'Union des zemstva et, après 1917, dans l'organisation de la nouvelle administration statistique de l'État bolchevik.

La participation des statisticiens à l'activité de différentes sociétés ou commissions locales en liaison avec l'administration du zemstvo a par ailleurs contribué à leur insertion dans l'espace de sociabilité de l'élite intellectuelle et politique locale constituée autour du conseil du zemstvo. En outre, certains d'entre eux côtoyaient les responsables du zemstvo, mais aussi des autres administrations de la ville, dans des sociétés qui n'étaient caractérisées par aucun lien professionnel avec le zemstvo ni même aucun engagement social, par exemple le Yacht-Club. Tel était le cas de A.F. Milovzorov, qui en était encore membre en 1917186. D'autres, comme N. N. Sirotinin, pouvaient côtoyer les administrateurs du zemstvo et de la ville dans un lieu aussi inattendu qu'un champ de courses de chevaux ${ }^{187}$. Pour sa part, V. I. Serebrjakov s'adonnait chaque fin d'été aux plaisirs des vendanges et de la vinification dans sa propriété de Gelendžik, sur la mer Noire188.

Ceci conduit à dresser un portrait de ces statisticiens plus nuancé que celui, courant dans l'historiographie soviétique, du populiste qui parcourait les campagnes, du socialiste révolutionnaire ou du marxiste confondant vie personnelle et militantisme politique. Les profils politiques et les comportements sociaux de ces hommes étaient plus variés que cela. Leur origine sociale aussi était diverse, de plus en plus diversifiée au fur et à mesure des recrutements. Si, parmi les premiers directeurs du bureau, deux étaient issus de familles nobles, S. A. Harizomenov et N. N. Černenkov, le suivant, V. I. Serebrjakov était fils de meščanin moscovite. Parmi les directeurs adjoints, un seul était noble, V. M. Obuhov. N. I. Rakitnikov était fils de paysan émancipé par la loi de 1861, A. F. Milovzorov était fils de činovnik non noble, I. I. Gil'genberg était issu d'une famille de colons allemands du sud de la gubernija ${ }^{189}$. En 1902, sur les douze statisticiens du bureau, deux

186. GASO, fonds du Yacht-Club de Saratov, f. 373, op. 1, d. 1,1. 124.

187. GASO, fonds privé d'Ol'ga Sirotinina, f. R-3649, op. 1, d. 420,1. 103ob.

188. GASO, f. 53, op. 1, d. 48, 11. 138, 147, 150, 161, 176.

189. Pour une analyse de l'origine sociale des statisticiens du bureau de Saratov, voir M. Mespoulet, op. cit., chap. 5. 
étaient d'origine noble, trois avaient un père meščanin, trois étaient fils de paysan, trois avaient un père činovnik non noble ${ }^{190}$.

\section{Conclusion}

Cette étude du groupe des statisticiens du zemstvo de Saratov et de leur mode d'insertion dans la vie locale de leur province permet de dégager différents éléments touchant à la fois à l'histoire des professions intellectuelles et à l'histoire de la statistique en Russie. Engagés pour une tâche qui pouvait n'apparaître que technique, ces hommes furent bien plus que de simples techniciens des chiffres. Ils observaient l'économie et la société de leur gubernija avec des outils et des grilles d'analyse élaborés au sein de leurs sociétés de statistique et de leurs congrès professionnels nationaux, et adaptés ensuite, si nécessaire, à la réalité locale.

En fait, les zemstva ont offert aux statisticiens un vaste terrain d'application et d'expérimentation de leurs méthodes et de leurs techniques à l'échelle de l'ensemble du territoire des trente-quatre gubernii administrées de cette manière. La méthodologie des recensements par ménage, celle aussi des premiers sondages, ont été construites ainsi, dans un mouvement continu d'aller et retour entre une réflexion théorique menée au sein d'instances professionnelles et scientifiques nationales et une expérimentation sur le terrain conduite dans ces provinces. Ceci donne toute son originalité à la statistique des zemstva, forme particulière d'une statistique régionale incluse dans un espace national de construction du savoir. En cela, elle a été bien plus qu'une statistique régionale centrée seulement sur des préoccupations et des objets d'enquête locaux.

Les caractéristiques de la constitution du corps professionnel des statisticiens des zemstva, en particulier leurs trajets de formation et les itinéraires d'accès à leurs postes, expliquent en partie cela. Les conditions mêmes de la commande institutionnelle en sont une autre raison. Née des besoins locaux en informations chiffrées des zemstva, inséparable du mouvement libéral des zemstva et des formes organisationnelles que celui-ci a essayé de se donner, la statistique des zemstva s'est développée dans une configuration qui a été commune à l'ensemble des professions intellectuelles de ces administrations territoriales. Les sociétés et les congrès professionnels ont contribué à structurer ces groupes professionnels en même temps que le mouvement libéral lui-même. La statistique des zemstva s'est construite ainsi, au carrefour d'un processus de professionnalisation et d'une dynamique politique. On a là une particularité de la configuration nationale des formes du développement de la production statistique en Russie de 1880 à 1917.

L'étude des conditions de production et des travaux de cette forme de statistique régionale en Russie apparaît alors indispensable pour comprendre le processus de construction de ce qui allait devenir une statistique nationale dans le cadre de

190. GASO, f. 25, op. 1, d. 1427, 11. 17-20. En ce qui concerne le douzième homme, K. A. Mačeevič, aucune précision n'a pu être trouvée dans les documents d'archives du bureau. 
l'Union des zemstva. Tout comme l'Union a occupé un espace laissé vide par l'État tsariste et est devenue, pour certains, «une véritable administration de remplacement $\gg 191$, la communauté professionnelle des statisticiens des zemstva, organisée en commission statistique de l'Union, a pris la place d'un Comité central de la statistique tsariste devenu inexistant. Dans une situation où l'État tsariste avait de plus en plus de mal à assumer sa fonction de gouvernement, la statistique d'État s'est effacée au profit de celle des zemstva, promue officiellement en statistique nationale, à défaut d'être d'État.

Ainsi s'éclaire le processus qui a pu, de manière paradoxale, conduire ensuite l'État bolchevik centralisateur à organiser son administration statistique d'État sur la base des bureaux de statistique des zemstva et de leur personnel. De fait, il n'a fait que transformer en administration d'État des institutions qui fonctionnaient déjà à l'échelle nationale. Ceci peut expliquer par ailleurs les tensions des premières années de fonctionnement de la nouvelle Direction centrale de la statistique, la CSU ${ }^{192}$, mise en place par la réforme du 25 juillet 1918. «L'alliance libérale-radicale » des zemstva avait laissé des traces en statistique. Certains des premiers responsables de la CSU avaient appartenu au parti cadet, par exemple N. A. Kablukov, A. F. Fortunatov, A. A. Kaufman, R. M. Orženskij. Ils restaient attachés à une conception de la production des données statistiques qui ne correspondait pas toujours au projet des bolcheviks dans ce domaine. Dans les régions, les bureaux de gubernija ont connu une remarquable continuité du personnel, des structures et des travaux tout le long de la guerre civile ${ }^{193}$. L'éloignement du centre provoqué par la confusion de cette période n'est sûrement pas étranger à ce phénomène ${ }^{194}$. En particulier, les bureaux les plus anciens ont lutté pour continuer à consacrer une partie de leur travail aux besoins de la gestion économique locale de leur province ${ }^{195}$. La raison statistique résistait au nouvel ordre politique.

C'était bien là le mode d'expression caractéristique d'anciens professionnels des zemstva qui avaient, en fin de compte, toujours travaillé aux deux niveaux, local et national. Enracinés professionnellement dans leur gubernija, ils n'en ressentaient pas moins leur appartenance à une communauté nationale, professionnelle, intellectuelle et scientifique, politique également pour certains. Acteur local à identité double, le statisticien du zemstvo n'était pas mort avec la révolution d'Octobre. La manière dont, en septembre 1920, un homme qui avait été aussi

191. Voir R. Philippot, op. cit.,pp. 148-151.

192. La CSU (Central'noe statističeskoe upravlenie) a été créée par la réglementation du 25 juillet 1918, suivie de celle du 3 septembre pour l'organisation des bureaux régionaux.

193. Cf. M. Mespoulet, op. cit., chap. 3-5.

194. Jusqu'au printemps 1921, la province de Saratov faisait partie des régions les plus mal contrôlées par le pouvoir bolchevik. À ce sujet, voir notamment D. J. Raleigh, ed., A Russian civil war diary : Alexis Babine in Saratov, 1917-1922, Durham - Londres, Duke University Press, 1988.

195. Cf. M. Mespoulet-Buono, « Les relations entre centre et régions au moment de la mise en place des bureaux statistiques des gubernii. L'exemple du gubstatbjuro de Saratov, 19181923 », Cahiers du Monde russe, 4, 1997, pp. 489-509. 
engagé au niveau national que N. I. Rakitnikov désignait l'ensemble des statisticiens de Saratov par l'expression «nam, kak mestnym ljudjam» (Pour nous, qui vivons sur place) ${ }^{196}$, laisse supposer que ce sentiment d'appartenance double a survécu un certain temps parmi les anciens cadres du zemstvo. Peut-être aussi certains, comme N. I. Rakitnikov, pensaient-ils que la seule manière de sauvegarder une parole autre face à un État bolchevik de plus en plus centralisateur était de se réclamer d'un autre lieu?

Centre d'études du monde russe, soviétique et post-soviétique

EHESS

54, bd Raspail

75006 Paris

e-mail : Martine.Mespoulet@univ-angers.fr

196. GASO, f. R-1, op. 1, d. 79, 1. 2ob. N. I. Rakitnikov employa cette expression au cours d'une réunion du conseil de statistique de la gubernija consacrée à l'organisation du traitement local des données du recensement de 1920. 